NBER WORKING PAPER SERIES

\title{
GROWTH ACCOUNTING WITH MISALLOCATION: OR, DOING LESS WITH MORE IN SINGAPORE
}

\author{
John Fernald \\ Brent Neiman \\ Working Paper 16043 \\ http://www.nber.org/papers/w16043 \\ NATIONAL BUREAU OF ECONOMIC RESEARCH \\ 1050 Massachusetts Avenue \\ Cambridge, MA 02138 \\ June 2010
}

We thank Jonathan Anderson, Robert Barro, Susanto Basu, Jeff Campbell, Davin Chor, Erwin Diewert, Dan Fineman, Chang-Tai Hsieh, Boyan Jovanovic, Greg Mankiw, Justin Wolfers, Alwyn Young, and seminar participants at several institutions for helpful discussions. We are grateful to several anonymous referees, the editor, and coeditor of the AEJ: Macro, Steve Davis and John Leahy, for their comments and suggestions. David Thipphavong and Titan Alon provided excellent research assistance. Earlier versions of this paper circulated under the titles, "Measuring Productivity Growth in Asia: Do Market Imperfections Matter?" and "Measuring the Miracle: Market Imperfections and Asia's Growth Experience." The views are our own and do not necessarily reflect those of anyone else affiliated with the Federal Reserve System or the National Bureau of Economic Research.

NBER working papers are circulated for discussion and comment purposes. They have not been peerreviewed or been subject to the review by the NBER Board of Directors that accompanies official NBER publications.

(C) 2010 by John Fernald and Brent Neiman. All rights reserved. Short sections of text, not to exceed two paragraphs, may be quoted without explicit permission provided that full credit, including $\odot$ notice, is given to the source. 
Growth Accounting with Misallocation: Or, Doing Less with More in Singapore

John Fernald and Brent Neiman

NBER Working Paper No. 16043

June 2010

JEL No. E01,F43,O4

\begin{abstract}
$\underline{\text { ABSTRACT }}$
We derive aggregate growth-accounting implications for a two-sector economy with heterogeneous capital subsidies and monopoly power. In this economy, measures of total factor productivity (TFP) growth in terms of quantities (the primal) and real factor prices (the dual) can diverge from each other as well as from true technology growth. These distortions potentially give rise to dynamic reallocation eIlects that imply that change in technology needs to be measured from the bottom up rather than the top down. We show an example, for Singapore, of how incomplete data can be used to obtain estimates of aggregate and sectoral technology growth as well as reallocation eIIects. We also apply our framework to reconcile divergent TFP estimates in Singapore and to resolve other empirical puzzles regarding Asian development.
\end{abstract}

\author{
John Fernald \\ Research Department, Mail Stop 1130 \\ Federal Reserve Bank of San Francisco \\ 101 Market St \\ San Francisco, CA 94105 \\ john.fernald@sf.frb.org \\ Brent Neiman \\ University of Chicago \\ Booth School of Business \\ 5807 South Woodlawn Avenue \\ Chicago, IL 60637 \\ and NBER \\ brent.neiman@chicagobooth.edu
}




\section{Introduction}

Many countries - rich and poor, fast growing and slow-have market distortions that affect the economic interpretation of productivity statistics. Some distortions reflect intentional government policies such as capital subsidies or preferential tax treatment that favor particular firms or activities. Others reflect monopoly power that can lead to pure economic profit. These distortions, in theory and practice, influence measures of total factor productivity in terms of quantities (the primal approach) and real factor prices (the dual). We derive aggregate growth accounting implications for a two-sector economy with heterogeneous capital subsidies and monopoly power. In this economy, measures of primal and dual TFP growth can diverge from each other and from true technology growth.

One set of distortions arises from policy interventions. Favored producers might receive subsidized financing or preferential tax treatment; foreign firms might be offered benefits to encourage direct investment. Subsidies and benefits are often difficult to quantify and can lead the actual user cost of capital to diverge from measures observed by a statistician. Even at a firm level, measured dual TFP growth, which is based on changes in real factor payments, will then not generally equal true technology growth; primal TFP growth, in contrast, does not directly use the measured cost of capital and is less sensitive to this unobserved favoritism.

A second set of distortions reflects monopoly power. Such monopoly power might reflect entry barriers that protect powerful incumbents or state-owned firms, leading prices to be a markup over marginal cost. Markups also cause problems for measurement because they drive a wedge between observed factor shares in revenues and output elasticities. For example, in the two-factor case with constant returns to scale, the labor elasticity of output is measured as labor's share of revenues and the capital elasticity of output can be inferred as the residual share. But economic profits break both of these relationships. The monopoly wedge generally implies, again, that measures of firm-level dual and primal TFP growth differ from each other and from technology growth.

Unobserved heterogeneity across producers with respect to both of these distortions causes additional problems. In our two-sector framework, aggregate technology cannot generally be obtained from aggregate data alone; it is necessary to build from the bottom up. The reason is that aggregate TFP estimates in this economy potentially include reallocation effects, since the same factor of production has a different social valuation in different uses. These effects, which reflect how capital market and other distortions influence the measured growth rate of TFP relative to technology, are 
the dynamic analog to the effect of misallocations in the cross-section and the resulting reduction in the aggregate level of TFP focused on in recent papers. ${ }^{1}$

We apply our framework to Singapore, a prominent puzzle in growth accounting. Young's (1992, 1994, 1995) careful primal growth accounting established the conventional wisdom that Singapore's rapid development did not involve TFP growth. Two decades of growth of nearly 8 percent per year reflected massive accumulation of capital and labor along with negative TFP growth. Hsieh's (2002) dual TFP accounting challenged this view, finding that TFP grew at a moderate positive pace. Table 1 compares these primal and dual estimates for Singapore as well as the other newly industrialized economies (NIEs) of Hong Kong, Korea, and Taiwan. The conflicting results for Singapore reflect the following puzzle. Labor's share in income was generally stable or rising. Hence, the rising capital-output ratio behind the weak primal TFP growth in Singapore implies a sharp decline in returns to capital; but, reasonable user-cost measures are flat.

We provide qualitative and quantitative evidence that capital subsidies, differential tax treatment, and pure profits played an important role in Singapore's economy. This is an example of a very successful economy that had the types of distortions we discuss. Our theoretical framework implies that, to measure technology, we in principal need to build from the bottom up — measuring technology separately for the favored and unfavored sectors. A challenge is that the detailed data necessary to do these computations directly do not exist. However, we show how to combine partial and incomplete data to measure aggregate technology as distinct from standard TFP, which may include reallocation and other effects.

Our results suggest that, for firms receiving preferential treatment, even Young's primal results were insufficiently pessimistic: Output grew nearly 10 percent per year for two decades, with negative technology growth. Since this sector received large quantities of foreign direct investment, our results suggest that policies designed to lure FDI did not, in fact, raise the level of technology (through technology transfer or otherwise). The unfavored sector had annual output growth of about 6 percent with positive technology growth.

Overall, technology growth in Singapore was slightly negative and, despite sizeable distortions, was not in fact much different from Young's primal estimates. This finding has at least two implications for measurement. First, capital reallocation effects in Singapore had only a quantitatively

\footnotetext{
${ }^{1}$ The burgeoning literature on resource reallocation and misallocation includes, for example, Restuccia and Rogerson (2009), Hsieh and Klenow (2010), and Banerjee and Moll (2010). Much of this literature focuses on developing countries, but many of the same issues apply to rich countries. For example, Basu and Fernald (2001) emphasized reallocations over the business cycle related to heterogeneity in factor prices and markups.
} 
minor impact on long-term productivity growth, despite sizeable differences across sectors in the returns and growth rates of capital. In particular, we find that reallocation of capital towards uses where it is less valuable (with a lower return) reduces productivity relative to technology at a rate of about 0.1 percent per year. This finding suggests that, in practice, the growth-rate implications of the misallocation literature may, plausibly, be quite small. Second, in the case of Singapore, standard TFP estimates such as Young's, which use a labor-share estimate of about $1 / 2$, provide more accurate estimates of technology growth than aggregate cost-based measures which, in Singapore's case, would use a labor share that is more "standard" of around 2/3. An aggregate cost-based measure generates larger reallocation effects that boost measured productivity growth relative to true technology growth. Hence, if one has access only to aggregate data, then "correcting" the factor shares to better reflect costs can lead to worse estimates of aggregate technology growth.

Further, we show how pure profits and unobserved heterogeneity in user costs can quantitatively resolve the puzzling mismatch between Hsieh's dual and Young's primal TFP calculations for Singapore. We replicate the exercise in the other NIEs to demonstrate that, consistent with these previous growth accounting results, it does not imply large dual-primal TFP gaps for Hong Kong, Korea, and Taiwan.

Finally, we note the implication of our calculations that labor's share of production costs was decreasing in most of the NIEs, despite labor's flat or rising share in revenue. Economic profit shares drove wedges between factor shares in revenues and in costs. Several international tradebased descriptions of Asia's growth, such as Ventura (1997) and Romalis (2004), involve structural transformations toward capital-intensive sectors and imply a decline in labor's share. Hence, in contrast to a face-value interpretation of the original growth accounting results, our explanation also allows an important role for trade in the NIEs' sustained rapid growth.

In sum, we identify pitfalls in interpreting growth accounting results, and then apply our analysis to Singapore and, to a lesser extent, the other NIEs. Section 2 considers primal and dual growth accounting exercises with empirically prevalent distortions. Section 3 turns to the case study of Singapore, documenting that heterogeneity in the user cost and monopoly power were important features of that economy. Section 4 shows how to estimate technology in this economy, despite the lack of complete data. Section 5 applies our framework more broadly to puzzles in Asia's development, including resolving the Young-Hsieh puzzle and finding evidence of a shift towards capital-intensive industries. We then conclude. 


\section{Growth Accounting in a Two-Sector Model with User-Cost Dif- ferences and Pure Profits}

We model a two-sector partial equilibrium environment in which one sector earns pure profits and has cheaper access to capital (reflecting capital subsidies and/or preferential tax rates). These features are likely present in many developing and emerging economies and we later show that they reconcile conflicting growth accounting estimates for Singapore. To begin, we describe the firm problem. Next, we relate measures of primal and dual TFP growth to sectoral technology growth and to each other. Finally, we consider how measured aggregate TFP growth compares with actual aggregate technology growth. We show that profits and unobserved heterogeneity in user costs can drive a wedge between the dual and the primal, and render both imperfect estimates of technology growth.

\subsection{A Two-Sector Environment}

Firms are indexed by $i=F$ or $U$ (ultimately, "favored" and "unfavored"). They use homogeneous capital $K$ and labor $L$, with $K_{t}=K_{F, t}+K_{U, t}$ and $L_{t}=L_{F, t}+L_{U, t}$. Production functions are Cobb-Douglas: $Y_{i, t}=A_{i, t} K_{i, t}^{\alpha_{i}} L_{i, t}^{1-\alpha_{i}}$, where $A_{i, t}$ is the firm's technology.

Firms are equity-financed and seek to maximize the present discounted value of cash flows. Cash flow each period equals after-tax revenues net of wages and capital expenditures: (1 $\left.\tau_{i, t}\right)\left(P_{i, t}\left(Y_{i, t}\right) Y_{i, t}-W_{t} L_{i, t}\right)-\left(1-\kappa_{i, t}-\tau_{i, t} D_{i, t}\right) q_{t} I_{i, t}$. Firms take the wage, $W_{t}$, as given and deduct wage payments before paying taxes at rate $\tau_{i, t} . q_{t}$ is the price of capital goods. $D_{i, t}$ is the present value of depreciation allowances in the tax code per dollar of investment, and is paid as an

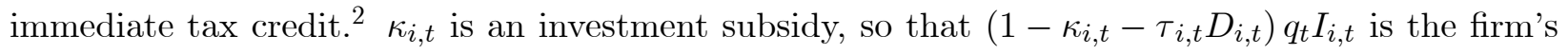
effective net expenditure on capital. If the firm has market power, then price $P_{i, t}$ depends on its choice of output: $P_{i, t}\left(Y_{i, t}\right) \cdot \rho_{t}$ is the nominal interest rate between $t-1$ and $t$ so that $\prod_{j=0}^{t}\left(1+\rho_{t}\right)^{-1}$ is the firm's discount rate from period 0 to period $t$ (with $\left.\rho_{0} \equiv 0\right)$.

With perfect foresight, the firm's problem is:

$$
\operatorname{Max} \sum_{t=0}^{\infty}\left(\prod_{j=0}^{t}\left(1+\rho_{t}\right)^{-1}\right)\left(\left(1-\tau_{i, t}\right)\left(P_{i, t}\left(Y_{i, t}\right) Y_{i, t}-W_{t} L_{i, t}\right)-\left(1-\kappa_{i, t}-\tau_{i, t} D_{i, t}\right) q_{t} I_{i, t}\right),
$$

subject to initial capital $K_{i, 0}$, the production function, and the constraint that capital input depends

\footnotetext{
${ }^{2}$ With constant tax rates, this formulation is equivalent to allowing firms to deduct depreciation each period against income before paying taxes. $D_{i, t}$ is the present value of these deductions.
} 
on investment $I_{i, t}$ and depreciation $\delta: K_{i, t+1}=(1-\delta) K_{i, t}+I_{i, t}$.

The first-order condition for labor yields that the output elasticity is a markup $\mu_{i, t}$ over the share of payments to labor in total revenue, $s_{L_{i, t}}$ (see, e.g., Hall 1990):

$$
1-\alpha_{i}=\mu_{i, t} \frac{W_{t} L_{i, t}}{P_{i, t} Y_{i, t}} \equiv \mu_{i, t} s_{L_{i, t}}
$$

where $\mu_{i, t}=\left(1+\left(\partial P_{i, t} / \partial Y_{i, t}\right)\left(Y_{i, t} / P_{i, t}\right)\right)^{-1}$. With perfect competition, price is not affected by the firm's output, so $\mu_{i, t}=1$. Similarly, the Euler equation for capital implies that the output elasticity is a markup over the share of payments to capital in total revenue, $\alpha_{i}=\mu_{i, t}\left(R_{i, t} K_{i, t}\right) /\left(P_{i, t} Y_{i, t}\right) \equiv$ $\mu_{i, t} s_{K_{i, t}}$, where capital's cost is calculated with an implied rental rate or user cost of capital:

$$
R_{i, t}=\frac{1}{1-\tau_{i, t}}\left(\left(\frac{1+\rho_{t}}{q_{t} / q_{t-1}}\right)\left(1-\kappa_{i, t-1}-\tau_{i, t-1} D_{i, t-1}\right)-(1-\delta)\left(1-\kappa_{i, t}-\tau_{i, t} D_{i, t}\right)\right) q_{t} .
$$

Let $\widehat{j}=d J / J$ be the percent change in variable $J$, so that $\left(1+\rho_{t}\right) /\left(q_{t} / q_{t-1}\right) \approx 1+\rho_{t}-\widehat{q_{t}}$. If $\tau_{i} D_{i}$ and $\kappa_{i}$ are constant between $t-1$ and $t$, then $R_{i, t}$ takes the familiar form: ${ }^{3}$

$$
R_{i, t}=\left(\rho_{t}+\delta-\widehat{q_{t}}\right)\left(\frac{1-\kappa_{i, t}-\tau_{i, t} D_{i, t}}{1-\tau_{i, t}}\right) q_{t} \equiv\left(\rho_{t}+\delta-\widehat{q_{t}}\right) T_{i, t} q_{t}
$$

where $T_{i}$ is a wedge from taxes, capital subsidies, and depreciation allowances.

The user cost is the implicit cost of using or renting capital for one period; it is capital's counterpart to the wage. The firm must earn an after-tax return to cover interest plus depreciation. The wedge $T_{i}$ captures taxes or subsidies that affect the pre-tax return the firm must earn to achieve this after-tax return. The purchase price of capital is effectively $\left(1-\kappa_{i, t}-\tau_{i, t} D_{i, t}\right) q_{t}$, so reducing investment subsidies or depreciation allowances raises the user cost, as does increasing $\tau_{i}$.

Instantaneous economic profits are:

$$
\Pi_{t, i}=P_{t, i} Y_{t, i}-R_{t, i} K_{t, i}-W_{t} L_{t, i}
$$

The profit share is $s_{\Pi t, i} \equiv \Pi_{t, i} /\left(P_{t, i} Y_{t, i}\right)=1-s_{L t, i}-s_{K t, i}=\left(\mu_{t, i}-1\right) / \mu_{t, i}$. With constant returns, a markup $\mu_{t, i}>1$ leads to pure profits. Henceforth, when possible, we omit time subscripts.

\footnotetext{
${ }^{3}$ See Hall and Jorgenson (1967). Auerbach (1983) and Hassett and Hubbard (2002) survey the vast literature on the user cost. Personal taxes affect capital taxation but not the user cost if firms take the interest rate as given. We have abstracted from property taxes. These were unimportant in Korea and Hong Kong, and moved over time with corporate tax rates in Singapore and Taiwan; see Asher (1989) and Tanzi and Shome (1992).
} 


\subsection{Recovering Technology Growth with the Primal and Dual}

Differentiating the production function, sectoral technology growth from the primal (quantities) is:

$$
\widehat{a}_{i}=\widehat{y}_{i}-\alpha_{i} \widehat{k}_{i}-\left(1-\alpha_{i}\right) \widehat{l}_{i}
$$

From the first-order conditions, the weights are factor shares in cost: $\alpha_{i}=R_{i} K_{i} /\left(R_{i} K_{i}+W_{i} L_{i}\right)$.

The dual approach also requires factor shares, but uses them to weight growth of real factor prices rather than factor quantities. Differentiating (2), substituting in relation (3), and rearranging terms yields sectoral technology growth as:

$$
\widehat{a}_{i}=\left(1-\alpha_{i}\right)\left(\widehat{w}_{i}-\widehat{p}_{i}\right)+\alpha_{i}\left(\widehat{r}_{i}-\widehat{p}_{i}\right)+\frac{s_{\Pi_{i}}}{1-s_{\Pi_{i}}} \widehat{s}_{\Pi_{i}}
$$

where $\widehat{s}_{\Pi_{i}}=\widehat{\pi}_{i}-\widehat{p}_{i}-\widehat{y}_{i}$ is the growth rate of sector $i$ 's profit share. Intuitively, if technology improves then someone gets paid more per unit of output - either a factor of production (labor or capital), or the owners of the firm. In principal, estimates of the growth in the user cost $\left(\widehat{r}_{\text {Dual }}\right)$ and wage $\left(\widehat{w}_{\text {Dual }}\right)$ might come from data independent of the national accounts. If the statistician accurately estimates the cost-shares $\alpha_{i}$, correctly measures factor price growth (including taking into account the tax wedge $T_{i}$, so that $\widehat{r}_{\text {Dual }}=\widehat{r}_{i}$ and $\widehat{w}_{D u a l}=\widehat{w}_{i}$ ), and has an accurate measure of the level and growth of profit's share, she would correctly estimate sectoral technology growth.

Growth in aggregate output, technology, and measured TFP reflect these sectoral values. The Divisia index of aggregate output growth is share-weighted sectoral growth: $\widehat{y} \equiv \omega_{F} \widehat{y}_{F}+\omega_{U} \widehat{y}_{U}$, where the nominal output share of sector $i$ is $\omega_{i} \equiv P_{i} Y_{i} /\left(P_{F} Y_{F}+P_{U} Y_{U}\right) \equiv P_{i} Y_{i} / P Y$. (Aggregating output with nominal output shares is sensible since these shares reflect relative prices, which are generally equated to purchasers' relative valuations.) With Cobb-Douglas production functions:

$$
\widehat{y}=\left(\omega_{F} \widehat{a}_{F}+\omega_{U} \widehat{a}_{U}\right)+\left(\omega_{F} \alpha_{F} \widehat{k}_{F}+\omega_{U} \alpha_{U} \widehat{k}_{U}\right)+\left(\omega_{F}\left(1-\alpha_{F}\right) \widehat{l}_{F}+\omega_{U}\left(1-\alpha_{U}\right) \widehat{l}_{U}\right)
$$

The first term, $\widehat{a} \equiv \omega_{F} \widehat{a}_{F}+\omega_{U} \widehat{a}_{U}$, tells us how much aggregate output rises because of technological change, holding labor and capital in the two sectors fixed (so that the second and third terms are zero). Given this property, it is a natural measure of aggregate (and average) technology change. In general, as we discuss in the next subsection, it needs to be calculated from the "bottom up," using sectoral technology estimates performed as in (3) or (4). 


\section{$2.3 \quad$ Pitfalls in Standard Growth Accounting Approaches}

TFP estimates capture more than just technology, whether at a sectoral or an aggregate level. Standard primal TFP growth is ordinarily defined using labor's share of revenue, $s_{L_{i}}$, rather than shares in cost, to weight input growth. At a sectoral level:

$$
\widehat{T F P}_{\text {Primal }, i} \equiv \widehat{y}_{i}-\left(1-s_{L_{i}}\right) \widehat{k}_{i}-s_{L_{i}} \widehat{l}_{i}
$$

The share of payments to labor $s_{L_{i}}$ is easiest to measure so capital's weight is a residual $\left(1-s_{L_{i}}\right)$. If firms have market power, $\mu_{i}>1$, the primal TFP calculation (5) does not, in general, equal technology change $\widehat{a}_{i}$. In particular, from (3) and the first-order conditions, we find:

$$
\widehat{a}_{i}=\widehat{T F P} P_{\text {Primal }, i}+\left(\mu_{i}-1\right) s_{L_{i}}\left(\widehat{k}_{i}-\widehat{l}_{i}\right)
$$

With pure profits, labor's revenue share overweights capital and underweights labor (see Hall, 1990). If capital grows faster than labor, then technology growth exceeds measured primal TFP growth.

Now consider dual (factor price) estimates. As a benchmark, suppose the statistician uses the same data as the primal (namely, nominal and real output, wage and labor input, and capital input) but cannot distinguish economic profits per unit of capital in sector $i, \Pi_{i} / K_{i}$, from the user cost, $R_{i}$. A natural implied "dual" return on capital would take payments to capital as a residual, yielding a return of $\left(P_{i} Y_{i}-W L_{i}\right) / K_{i}=\left(R_{i}+\Pi_{i} / K_{i}\right)$. Then, totally differentiating the accounting identity that $P_{t, i} Y_{t, i}=W_{t} L_{t, i}+\left(R_{i}+\Pi_{i} / K_{i}\right) K_{t, i}$ and rearranging yields:

$$
\widehat{y}_{i}-s_{L_{i}} \widehat{l_{i}}-\left(1-s_{L_{i}}\right) \widehat{k_{i}}=s_{L_{i}}\left(\widehat{w}-\widehat{p_{i}}\right)+\left(1-s_{L_{i}}\right)\left(\left(r_{i}+\widehat{\pi_{i}} / k_{i}\right)-\widehat{p_{i}}\right) .
$$

The left-hand side is primal TFP growth from (5). Equation (6) thus shows that standard TFP growth can be estimated either from quantities or from share-weighted growth in real factor prices (the dual). If the data satisfy the accounting identity (i.e., they are internally consistent), then the results are identical. If $\mu_{i, t}>1$, then neither estimate, in general, equals technology growth.

Of course, the dual approach is useful if factor-price data are more easily available (or considered more reliable) than quantity data. Following Hsieh (2002), suppose the statistician continues to use $s_{L_{i}}$ and $\left(1-s_{L_{i}}\right)$ as weights and assumes away the import of (or cannot observe) taxes and subsidies. She measures the user cost for all firms as $R_{D u a l, i}=R_{\text {Dual }}=(\rho+\delta-\widehat{q}) q$. $\rho$ is some market rate, such as a bank rate. Even if $\rho$ appropriately measures the firm's discount rate, the 
user-cost estimate still differs from the firm's true user cost due to the tax/subsidy wedge, $T_{i}$, and so the statistician incorrectly estimates growth in this cost: $\widehat{r}_{D u a l, i}=\widehat{r}_{i}-\widehat{t}_{i}$. In such a case, and assuming $\widehat{w}_{D u a l}=\widehat{w}$, it can be shown that:

$$
\begin{aligned}
\widehat{T F P}_{\text {Dual }, i} & \equiv\left(1-s_{L_{i}}\right)\left(\widehat{r}_{\text {Dual }, i}-\widehat{p}_{i}\right)-s_{L_{i}}\left(\widehat{w}-\widehat{p}_{i}\right) \\
& =\widehat{a}_{i}\left(1-s_{\Pi_{i}}\right)-s_{\Pi_{i}} \widehat{\pi}_{i}-\left(1-s_{\Pi_{i}}\right)\left(1-\alpha_{i}\right) \widehat{t}_{i}
\end{aligned}
$$

If profits are always zero and $T_{i}$ is constant, then dual TFP growth equals technology growth. If either of these conditions fails, it does not.

The pitfalls so far refer to estimates with sectoral (or industry) data. But TFP estimates often use aggregate output and inputs - reflecting data availability as well as a desire for simple summary statistics (e.g., for cross-country comparisons). In distorted economies, measures of aggregate TFP capture resource reallocations as well as technology. Suppose the unfavored sector is perfectly competitive, but the favored sector $F$ charges a markup $\mu_{F}>1$ and may receive a capital subsidy or favorable tax treatment (so $T_{F}<T_{U}$ ). Some algebra (see Appendix A) shows that standard TFP growth (equation (5), calculated with aggregate data) is:

$$
\widehat{T F P} \equiv \widehat{y}-\left(1-s_{L}\right) \widehat{k}-s_{L} \widehat{l}=\widehat{a}+s_{\Pi}\left(\widehat{x}_{F}-\widehat{k}\right)+\Sigma_{K}
$$

$\widehat{x}_{F}=\alpha_{F} \widehat{k}_{F}+\left(1-\alpha_{F}\right) \widehat{l}_{F}$ is cost-share-weighted inputs in the favored sector. $s_{\Pi}\left(\widehat{x}_{F}-\widehat{k}\right)$ reflects the net effect of two channels by which markups affect aggregate TFP growth. First, with markups, a factor's output elasticity in the favored sector exceeds its share in revenue (see, e.g., equation (1)). Hence, this calculation does not fully account for the productive contribution of favored inputs, with undermeasurement of $s_{\Pi} \widehat{x}_{F}$. Second, standard TFP subtracts off $\left(1-s_{L}\right) \widehat{k}=\left(s_{K}+s_{\Pi}\right) \widehat{k}$. The $s_{\Pi} \widehat{k}$ portion does not reflect capital's marginal product, so it is added back.

The last term in (7):

$$
\Sigma_{K}=\frac{K_{F}}{K} \frac{K_{U}}{K} \frac{R K}{P Y}\left(\frac{R_{F}-R_{U}}{R}\right)\left(\widehat{k}_{F}-\widehat{k}_{U}\right)
$$

is a capital reallocation term: reallocating capital to sectors with higher user costs raises measured TFP relative to technology. Other things equal, a higher user cost implies a higher value of the marginal product of capital. Shifting capital to where it's more valuable raises output and productivity, even if technology and total inputs remain constant. 
At a sectoral level, a cost-based residual would appropriately measure technology, as equation (3) shows. But at an aggregate level, cost-based aggregate TFP growth also does not equal technology growth because of reallocation effects. Appendix A shows that:

$$
\widehat{y}-(1-\alpha) \widehat{l}-\alpha \widehat{k}=\widehat{a}+\frac{s_{\Pi}}{1-s_{\Pi}}\left(1-\omega_{F}\right)\left(\widehat{x}_{F}-\widehat{x}_{U}\right)+\frac{\Sigma_{K}}{1-s_{\Pi}} .
$$

The capital-reallocation term in (8) is a scaled-up version of the capital-reallocation term in (7). The "profits reallocation" term takes a different form, however, and reflects that output growth is aggregated using shares in total nominal output, whereas a cost-based residual effectively aggregates inputs using shares in total cost. Some algebra (see Appendix) shows that $s_{\Pi}\left(1-\omega_{F}\right) /\left(1-s_{\Pi}\right)$ is the difference between the share of the favored sector in output, $\omega_{F}$, and its share in costs. This wedge is large if profits (earned only in the favored sector) are large, but it is small if the favored sector is already a large share of the economy; intuitively, as the favored sector's share of output goes to its upper bound of one, the wedge between output and cost shares in the favored sector necessarily goes to zero. The profits-reallocation term implies that shifting resources towards the favored sector-where markups and profits are high-raises aggregate output and the cost-based residual, even if aggregate inputs don't change. ${ }^{4}$

Using the dual doesn't simplify the aggregation problem. Consider a counter example. Suppose $\alpha_{U}=\alpha_{F}$ and that the measured user cost and wages correspond to the unfavored sector. Then, a cost-based "aggregate" dual residual gives technology growth in that sector alone, irrespective of what is happening to favored technology.

The reallocation terms in (7) and (8) are the dynamic counterparts of the levels effects identified in the misallocation literature (e.g., Hsieh and Klenow, 2010). In order to do counterfactuals (such as asking what would happen if a distortion were eliminated), one needs the full general equilibrium model. For historical growth accounting, in contrast, one needs weaker assumptions, since (conditional on given distortions) equilibrium prices and quantities are observed. In particular, we need assumptions only about the production side of the problem to obtain a set of first-order conditions that allow us to interpret quantity changes; we do not need to make assumptions about the rest of the model. (The "cost" of using these weaker assumptions is that we cannot do counterfactuals).

The misallocation literature emphasizes how favoritism can reduce the level of productivity. Hsieh and Klenow, for example, focus on favorable access to capital. In growth rate terms, if

\footnotetext{
${ }^{4}$ A complementary intuition comes from noting that monopolists produce too little from a social perspective. Shifting resources towards a sector that underproduces raises aggregate output (and, generally, welfare).
} 
favoritism not only leads to $R_{F}<R_{U}$ but also leads to faster growth in favored capital $\left(\widehat{k}_{F}>\widehat{k}_{U}\right)$, then $\Sigma_{K}$ is negative. Other things equal, measured TFP falls relative to technology. The discussion above also highlights an additional effect, which plausibly works in the opposite direction. In our model, favored firms have monopoly power and underproduce. If these firms increase inputs more quickly (relative to $\widehat{k}$, with standard TFP; or relative to $\widehat{x}_{U}$ with cost-based TFP), then measured productivity rises. Hence, policies that encourage the growth of monopoly firms reduce an existing distortion. The net effect of these two terms on measured TFP growth is uncertain. In particular, if capital subsidies work to systematically shift resources towards the profitable, favored sector, then the profits term might plausibly be positive even though the capital-reallocation term $\Sigma_{K}$ is negative.

The major conclusions from this section are that, with significant and different distortions across sectors, estimating technology growth in principal requires building from the bottom up. Simple fixes - such as using cost-shares rather than revenue-shares, or doing dual rather than primal growth accounting - do not allow us to sidestep the aggregation issues. Sectoral distortions imply that observed factor-price data may be unrepresentative of the aggregate economy and create the possibility that reallocations affect aggregate productivity growth. Distinguishing technology change from these reallocations requires controlling for the distortions at a disaggregated level.

\section{Profits and User-Cost Differences in Singapore}

The model suggests features of economies that can theoretically cause primal and dual TFP calculations to diverge from each other as well as from technology growth. Singapore provides an interesting case study because of its enormous success in economic development as well as the controversy over the role of TFP growth in this development. This section documents that the distortions identified in the model matter in practice for Singapore.

Virtually every description of Singapore's transition from a poor country in the 1960s to a rich, modern economy cites the government's active intervention and enticement of vast inflows of FDI. "Favored" firms - primarily government-linked corporations (GLCs), statutory boards (SBs), and multinationals - benefited from favorable access to capital and land, preferential tax treatment, and earned large profits. ${ }^{5}$ Incentives, including tax preferences, increased over time.

\footnotetext{
${ }^{5}$ SBs are created by acts of Parliament and are accountable to particular ministries. For example, SBs provided utility services, telecom, and port operations. GLCs are incorporated under the Companies Act. Several state holding companies (e.g., Temasek) hold equity on behalf of the government; Singapore's Economic Development Board sometimes takes equity stakes, as well. See Ramirez and Tan (2003) and Economist Intelligence Unit (2004).
} 


\subsection{Capital Subsidies}

GLCs (where the government is a substantial shareholder) and wholly-government-controlled SBs contributed as much as 25 percent of Singapore's GDP by the late 1980's. ${ }^{6}$ GLCs, SBs, and multinationals had user costs of capital that likely differed from other firms. Special treatment (investment subsidies in our model) included direct government financing, implicit debt guarantees, and political connections. ${ }^{7}$ A major benefit was subsidized land access. Under the Land Acquisition Act, the government had authority to purchase land at its 1973 market price, which it leased to industrialists at rates that reflected the low acquisition price. As land prices rose, the land subsidy grew more valuable. Favored firms also received direct government credit. In the 1970s, government loans to foreign investors, GLCs, and commercially-oriented SBs amounted to about 20 percent of the total stock of bank loans to the private sector (these figures exclude sizeable housing loans). The average interest rate on these government commercial loans was about 3 percent less than the bank-lending rate used in Hsieh (2002) to implement a dual TFP calculation. (In the 1980s, the government stopped publishing the interest rate information. $)^{8}$

\subsection{Preferential Tax Treatment}

Tax-code changes reduced the wedge $T_{i}$ for all firms, but more for some than for others. For example, the statutory corporate tax rate fell from 40 percent to 33 percent in 1986 and to 32 percent in 1989. ${ }^{9}$ Figure 1A shows the statutory rate and two measures of taxes relative to income from Inland Revenue Authority Reports and from financial reports of corporations. The three measures all decline in the 1980s. But favored industries received much more generous tax treatment. Major legislative changes took place under the Economic Expansion Incentives (Relief from Income Tax) Act. The 1967 Act (as amended in 1970) gave so-called "pioneer firms" a five-year tax holiday, i.e., a tax rate of zero. In 1975, the tax-holiday period was extended to 10 years. In 1984, pioneer status

\footnotetext{
${ }^{6}$ Late 1980s share is from IMF (1995). Department of Statistics (2001) argues that by the mid-90s, the GLC share of GDP was only a bit over 10 percent. But that calculation explicitly excludes widespread holdings of companies where the government owns less than 20 percent. As Ramirez and Tan (2003) point out, this narrower definition of GLCs excludes many companies in which the government has effective control.

${ }^{7}$ The Economist Intelligence Unit (1993) states: "Singapore's government relies heavily on incentives to attract foreign investment ... Investment incentives include tax holidays and concessions, accelerated depreciation schemes, favourable loan conditions, equity participation and high-quality industrial estates..." Burton (1995) claims that GLCs' "costs of capital are usually lower than for companies in the private sector." U.S. Embassy (2001) notes that "GLCs were given preferential rates by DBS Bank, itself a GLC."

${ }^{8}$ See Appendix B for data sources. Ermisch and Huff (1999) and Tan (2001) discuss the implicit land subsidy. In Schein's (1996) case studies, negotiations between the government and foreign investors over leases for favorable land parcels figure prominently.

${ }^{9}$ Appendix B details our data sources and construction of the series in the figures.
} 
was extended to selected service firms. In 1987, Singapore reduced the tax rate for firms ending their tax-holiday period from 40 percent to 10 percent. The share of manufacturing value added accounted for by pioneer firms rose from an average of 53 percent in the first half of the 1970s to about 64 percent in the second half of the 1980s.

Figure 1B shows that foreign manufacturing firms, who were major recipients of pioneer status, paid rates that were lower, and also fell more quickly - from about 40 percent to under 10 percent by 1990. Other firms' rates fell only to about 30 percent.

\subsection{Economic profits}

Ermisch and Huff (1999) and the Singapore Economic Committee (1986) argue that government SBs earned monopoly profits in public utilities and telecom. Consistent with these claims, the "current surpluses" of commercially-oriented SBs (included in national accounting profits) averaged 13 percent of GDP during 1975-1984 and 10 percent during 1985-1988. Ramirez and Tan (2003) find that listed GLCs have statistically significantly higher q-ratios than other listed firms.

Singapore's active enticement of FDI inflows also led to large profits. From 1972 to 1990, Singapore generated FDI inflows averaging almost 1/4 of gross fixed capital formation by offering a wide range of incentives that reduced production costs. Singapore figures prominently in the literature on tax havens, "low-tax jurisdictions that provide investors opportunities for tax avoidance" (See Desai, Foley, and Hines, 2006). Firms might locate intangible assets in Singapore or else adjust internal transfer prices to realize high profits there. Indeed, the average tax rate for U.S. multinationals in Singapore is consistently among the lowest in the world - about 30 percentage points below the unweighted mean in 1983, for example. Such profit shifting, as well as other subsidies that reduced operating costs, would lead to large reported economic profits. ${ }^{10}$

Industry estimates suggest very large profits. Kee (2002) estimates markups and returns to scale for Singaporean manufacturing industries as in Hall (1990). She finds that most industries have large markups of price over marginal cost; but, consistent with our model, few have correspondingly large increasing returns, implying very large profits. Indeed, in a pooled specification, Kee's estimates imply that pure profits exceed 50 percent (!) of manufacturing value-added. ${ }^{11}$

\footnotetext{
${ }^{10}$ If quantities of final output, capital, and labor are accurately measured, then "spurious" profits arising from transfer pricing are no different from other monopoly profits from the point of view of the model (though the "markup" is no longer related solely to the elasticity of demand). Costs shares for capital and labor are not likely to be affected, so a cost-based residual continues to properly measures technology; and the relationship between the primal and dual is also not affected (Equation (4), for example, was derived from (3) and an accounting identity).

${ }^{11}$ If $\gamma$ is the returns to scale parameter, then $\Pi /(P Y)=(\mu-\gamma) / \mu$. See, e.g., Basu and Fernald (2001).
} 
One striking piece of evidence consistent with large economic profits is Singapore's low labor share of revenue which, according to Young (1998), averaged 52 percent from 1970-90. As an accounting identity, $s_{L}=\left(1-s_{\Pi}\right)(1-\alpha)$, where $(1-\alpha)$ is labor's share in aggregate costs. For a given $\alpha$, as $s_{\Pi}$ rises, labor's share in revenue $s_{L}$ falls.

Could Young have made some mistake in calculating labor's share? Appendix B explores this hypothesis and corroborates Young's low estimate of $s_{L}$. In particular, since Young's work, Singapore Statistics has begun publishing data on GDP by income components (albeit starting only in 1980). From 1980 to 1990, compensation as a share of value added averaged 45 percent. (Labor income in these accounts includes not only wages and salaries, whether in cash or in kind, but also pension contributions such as employers' contributions to the Central Provident Fund and private pension/insurance funds.) This figure does not include unallocated proprietors' income from selfemployment, which averaged 8 percent of income over this period. Any reasonable allocation of this unallocated proprietors' income (such as $2 / 3$ to labor and $1 / 3$ to capital) would imply that labor's share was, indeed, about $1 / 2 .{ }^{12}$

$s_{L}$ could be very low if production were particularly capital intensive, so that $\alpha$ was high. A direct check is to estimate payments to capital $R K=\left(\rho_{t}+\delta-\widehat{q_{t}}\right) T_{t} q_{t} K_{t}$. Rotemberg and Woodford (1995) and Basu and Fernald (2002) use this approach to estimate that U.S. profits are low. We used investment data from the national accounts to measure $q_{t} K_{t}$ and $q_{t}$ (see Appendix B), Hsieh's lending-rate estimate of $\rho_{t}$, and an estimate of $T_{t}$ (averaged across favored and unfavored firms, but omitting any unobserved capital subsidies). The estimated $\alpha=R K /(R K+W L)$ averaged 36 percent during the 1970-90 period-high, but far short of $\left(1-s_{L}\right)$. The implied profit rate, $s_{\Pi}=\left(1-s_{L}-\alpha\right) /(1-\alpha)$, is 20 percent of GDP. If there were additional capital subsidies (as the anecdotes suggest), this direct estimate of $\alpha$ is overstated and $s_{\Pi}$ is understated.

An alternative check on $\alpha$ and $s_{\Pi}$, which does not require assumptions about the appropriate level of the user cost, comes from looking at industry structure. After all, it could be that Singapore has a high $\alpha$ because it specializes in capital-intensive industries. We combine national accounts data on industry structure with international data on factor shares by industry. We assume pure profits are relatively small in U.S. and E.U.-15 countries, and use their capital income shares (averaged across time and across countries) as a measure of $\alpha_{j}$ for each of the nine 1-digit industries,

\footnotetext{
${ }^{12}$ Singapore's Labor Force Survey indicates that in the 1980s, about 11 percent of the labor force were either self-employed or unpaid family workers. One way to allocate proprietors income is to assume that the these workers earned the same average wages as employees. Then $s_{L}=0.45 /(1-0.11)$, or 51 percent, close to Young's estimate.
} 
$j$, in the United Nations International Standard Industrial Classification (ISIC). ${ }^{13}$ At least for the U.S. and E.U., shares show modest variation over time or across countries; however, there are large and systematic differences in shares across industries. Thus, deviations from strict Cobb-Douglas in these data appear small relative to mean differences across industries. (Note that, if U.S. or E.U. industries earn pure profits, then using their factor shares as a benchmark will lead to estimates that understate profits in the NIEs.)

Table 2 shows results from this "industry structure" approach. Lines 1 and 2 show the level and growth in the "residual" share of capital and profits in revenues, $\left(1-s_{L}\right)$, as used by Young (1995) and Hsieh (2002). Lines 3 and 4 show the level and growth in the "true" capital cost share $\alpha=\sum_{j} \alpha_{j} \omega_{j}^{C}$, where $\omega_{j}^{C}=\left(W L_{j}+R_{j} K_{j}\right) / \sum_{j}\left(W L_{j}+R_{j} K_{j}\right)$ is an estimate of industry $j$ 's share of total costs. Line 7 gives the implied profit rate, $s_{\Pi}=\left(1-s_{L}-\alpha\right) /(1-\alpha)$. The estimated "true" capital revenue share $s_{K}$, line 5 , is the difference between the share of capital plus profit (line 1 ) and the profit share (line 7).

Estimating industry shares in total cost require assumptions about the distribution of profits. If the profit rate is equal across sectors, then $\omega_{j}^{C}=\omega_{j}$, the industry's observed share of GDP. For Singapore, the first column of results makes this assumption. The anecdotal evidence above, however, suggests that some but not all industries earned profits. The second column of results assumes that only some favored industries earn profits (albeit with all favored industries having the same profit rate). We defer discussion of the specific assumptions made (including the industry breakdown) until Section 4.1. The differences between these two columns reflects that favored industries (and thus, by assumption the more profitable ones) were also more capital intensive. Hence, the capital-intensive industries receive a lower weight in aggregate cost $\omega_{j}^{C}$ in the second

\footnotetext{
${ }^{13}$ We obtain industry factor shares from the EU KLEMS Growth and Productivity Accounts. These accounts provide consistent data for cross-country productivity comparisons, with industry measures of output, inputs, and factor payments from 1970-2005 for the United States, Japan, a number of European Union countries and several other developed economies. Most of the data originate from countries' national accounts; but they have been cleaned and modified as part of the EU KLEMS project in order to harmonize concepts and ensure consistent definitions and treatment. See O'Mahony and Timmer (2009) for a detailed description of the content and methodology for the EU KLEMS database. The EU-15 countries comprise Austria, Belgium, Denmark, Finland, France, Germany, Greece, Ireland, Italy, Luxembourg, the Netherlands, Portugal, Spain, Sweden and the United Kingdom. We use the March 2008 release at www.euklems.org.

For robustness, we also used industry cost-share estimates from Sarel (1997), who similarly measures capital shares from independent international sources on industry structure. His industry-share estimates are simple averages from 26 countries, in 1980 or 1990; the countries range from very poor countries like Cameroon and Nigeria to rich countries like the United States. The correlation between industry factor shares in EU KLEMS and Sarel is 0.94. As such, it is not surprising that our results are highly similar using this alternative measure.

The calculations might be misleading if the product mix within one-digit industries differs from the world norm. We obtained two-digit-manufacturing value-added data for Singapore in 1990 and applied factor shares (averaged 1980-1996) from Dale Jorgenson's U.S. data. The implied manufacturing capital share was 0.32, compared with 0.34 in EU KLEMS. Product mix thus cannot explain much of a gap between $\left(1-s_{L}\right)$ and $\alpha$.
} 
column than in the first (since some of their GDP weight, in column 1, reflects profits). ${ }^{14}$ Column 2 thus has a lower aggregate $\alpha$, which implies a higher aggregate profit rate.

Either set of estimates corroborates the direct and anecdotal evidence of pure profits in Singapore. Labor's share is strikingly low, so the residual share $\left(1-s_{L}\right)=s_{K}+s_{\Pi}$ (line 1) is about $1 / 2$. But our estimated capital cost share is only a bit above $1 / 3$ (line 3 ), implying a profit share of about 1/4 (line 7). This large profit share declined between 1 and 1.4 percent per year.

Table 2 includes, for comparison, estimates for the other NIEs, assuming an equal profit share across industries. Estimated profit shares in Korea and Hong Kong are both less than 5 percent. In Taiwan, the high labor share (about 3/4, from Young, 1995) implies a negative profit share. However, Young (2003) argues that his original labor-share estimate is too high because it inadvertently overadjusts for (imputed) proprietor's wage income; he does not provide a corrected figure. Thus, we interpret the Taiwan, Korea, and Hong Kong results as consistent with small pure profits.

In sum, quantitative approaches corroborate the anecdotal reports that Singapore had exceptionally large pure profits. ${ }^{15}$

\section{Measuring and Interpreting Technology Growth in Singapore}

We now assess technology change in Singapore and, as a by-product, describe the evolution of the two sectors and the aggregate economy. Section 2 emphasized that when sectors are heterogeneous, we need to measure technology from the bottom up. The main measurement challenge is the lack of direct data on inputs for the favored and unfavored sectors (Young, 1994, discusses this lack of reliable industry data). We show how to use partial data on the two sectors to derive appropriate estimates.

\subsection{Measuring Technology}

We estimate sectoral and aggregate technology by combining the relationships from Section 2 with a range of other data sources, including Young's $(1995,1998)$ primal, Hsieh's (2002) dual, our own

\footnotetext{
${ }^{14}$ If profit shares are equated across industries within the profit-making favored sector, then-within the favored and unfavored sectors separately - shares in output correspond to shares in cost. We can then estimate $\alpha_{F}$ and $\alpha_{U}$. Section 4.1 describes how we estimate sectoral labor shares. Given the $s_{L, F}$ and $\alpha_{F}$, we can obtain $s_{\Pi, F}$. $s_{\Pi}$ is then $\omega_{F} s_{\Pi, F}$.

${ }^{15}$ Studies for other countries also sometimes suggest that product market distortions lead to substantial economic rents. Blanchard and Giavazzi (2003) discuss the sharp decline in labor's income share in some European economies from the early 1980s to the mid-1990s; in Italy, for example, labor's share fell from almost 80 to about 60 percent. They attribute the decline to labor's reduced ability to capture the rents arising from product market restrictions. Such a large shift in rents implies that the rents themselves must be large.
} 
measurements of Singapore's market imperfections from Section 3, and the national accounts.

To preview, the key assumption is that the unfavored sector is perfectly competitive and receives no unobserved subsidies. Hence, the dual (with appropriate real factor prices and factor shares) accurately measures unfavored technology growth. We also assume that particular one-digit industries, for which we have national accounts data on output and prices as well as international data on factor shares, correspond to this competitive sector. We can then use these data to infer unfavored labor and capital growth that are consistent with the dual. In the favored sector, imperfect competition and unmeasured capital subsidies drive a wedge between standard measures of primal or dual TFP and technology. But we can use the estimates of unfavored inputs along with aggregate accounting relationships for capital and labor to back out favored inputs; the cost-based primal (3) then gives technology. Throughout, we assume that capital and labor are homogenous (which simplifies aggregate relationships) and that the nominal wage is equalized across sectors.

How do we apply these assumptions? First, we allocate one-digit ISIC industries wholesale to either the favored or the unfavored sectors. Note that, if the allocation is unclear, we want to err on the side of over-allocating to the favored sector, to ensure that the unfavored sector truly is competitive. In contrast, inappropriately including some competitive, unsubsidized activities in the favored sector might induce some reallocation effects within that sector, but are unlikely to substantially affect interpretation. The anecdotal evidence from Section 3 suggests that the favored sector comprised all or parts of the following industries: Manufacturing, Finance, Utilities, and Transport. The remaining sectors received little, if any, favorable treatment and we identify them with the unfavored sector: Agriculture and Fishing, Quarrying, Construction, Commerce, and Other Services. With this industry classification, the favored sector accounted on average for $\omega_{F}=59$ percent of output, and grew notably faster: From 1970-90, $\widehat{y}_{F}$ averaged 9.6 percent, and $\widehat{y}_{U}$ averaged 6.1 percent.

Second, as in Section 3.3, we assume Singapore's cost shares at the one-digit industry level equal the averages of U.S. and E.U.-15 industry factor shares taken from EU KLEMS. Given the industry decomposition, this assumption implies that unfavored industries are labor intensive: output-share-weighted $\alpha_{U}$ is only 23 percent, whereas $\alpha_{F}$ is 41 percent. Finally, for the sake of clarity and transparency, the discussion generally assumes that we can manipulate identities using average nominal shares (e.g., of favored and unfavored output) calculated over decades, even though the shares may be changing year-to-year. (Allowing for changing shares-i.e., doing all calculations year-by-year and then averaging across years - makes relatively little difference to results.) 
In the competitive and unsubsidized unfavored sector, dual TFP growth (4) equals technology growth. Calculating the dual requires three things: capital's share of the sector's costs $\left(\alpha_{U}=\right.$ $0.23)$, nominal wage growth deflated by the sectoral price index $\left(\widehat{w}-\widehat{p}_{U}\right)$, and the unfavored user cost of capital deflated by the sectoral price index $\left(\widehat{r}_{U}-\widehat{p}_{U}\right)$. Growth in real aggregate wages is $\widehat{w}-\widehat{p}=\widehat{s}_{L}+\widehat{y}-\widehat{l}=2.1$ percent, where we take growth in output $\widehat{y}$, labor's share $\widehat{s}_{L}$, and labor $\widehat{l}$ from Young (1998). We then solve for $\widehat{w}-\widehat{p}_{U}=(\widehat{w}-\widehat{p})+\left(\widehat{p}-\widehat{p}_{U}\right)=1.9$ percent, using sectoral and aggregate price deflators from the national accounts. ${ }^{16}$ Finally, we measure $\widehat{r}_{U}$ by averaging two of Hsieh's (2002) estimates of the real user cost, $\widehat{r}_{H \text { sieh }}-\widehat{p}$, that are based on the bank lending rate and the earnings-price ratio. ${ }^{17}$ (We omit Hsieh's third estimate, which uses return-on-equity (ROE) data since, as we discuss below, we question the reliability of the ROE data; we show in a robustness test in Table 3 that this makes little qualitative or quantitative difference.)

Hsieh explicitly ignored taxes and depreciation allowances, which potentially drive a wedge between observed $\widehat{r}_{\text {Dual }}$ and the actual change in unfavored user costs $\widehat{r_{U}}$. We use the data in Figure 1a along with estimates from the tax code on the present value of depreciation allowances, $D_{U}$, to calculate the unfavored tax wedge $T_{u}=\left(1-\tau_{U} D_{U}\right) /\left(1-\tau_{U}\right)$ under the assumption there are no unobserved subsidies in the unfavored sector (see Appendix B). $T_{u}$ declined over time, reflecting both a decline in the statutory tax rate from 0.40 to 0.32 , and an increase in the present value of depreciation allowances from about 0.6 before 1977 to about 0.75 after 1979. Together, the tax wedge for firms paying the statutory rate fell 0.7 percent per year, i.e. $\widehat{t}_{U}=-0.7$.

Combining Hsieh's user-cost estimates, our tax calculation, and the national accounts measure of the relative price yields: $\widehat{r}_{U}-\widehat{p}_{U}=\left(\widehat{r}_{H s i e h}-\widehat{p}\right)+\left(\widehat{p}-\widehat{p}_{U}\right)+\widehat{t}_{U}=0.6-0.1-0.7=-0.2$.

We now have all the elements required to calculate unfavored technology growth in (4):

$$
\begin{aligned}
\widehat{a}_{U} & =\left(1-\alpha_{U}\right)\left(\widehat{w}-\widehat{p}_{U}\right)+\alpha_{U}\left(\widehat{r}_{U}-\widehat{p}_{U}\right) \\
& =(0.77)(1.9)+(0.23)(-0.2)=1.5 \text { percent. }
\end{aligned}
$$

To measure favored sector technology, we use the cost-based primal, equation (3). As noted, $\widehat{y}_{F}$ is 9.6 percent and $\alpha_{F}$ is 41 percent. We also need growth in the sector's inputs, $\widehat{k}_{F}$ and $\widehat{l}_{F}$. To solve for these values, we first estimate their counterparts in the unfavored sector, $\widehat{k}_{U}$ and $\widehat{l}_{U}$. We then use the adding-up identities $\widehat{l}=\left(L_{F} / L\right) \widehat{l}_{F}+\left(1-L_{F} / L\right) \widehat{l}_{U}$ and $\widehat{k}=\left(K_{F} / K\right) \widehat{k}_{F}+\left(1-K_{F} / K\right) \widehat{k}_{U}$,

\footnotetext{
${ }^{16}$ To best preserve comparability of our estimates with Young, we use his measure of wage growth but could alternatively have used Hsieh's direct estimates.

${ }^{17}$ The measures cover different years. We weight by number of years covered to approximate the 1970-1990 period.
} 
which in turn require estimates of $\left(L_{F} / L\right)$ and $\left(K_{F} / K\right)$.

Starting with unfavored labor growth, we use the relationship $\widehat{l}_{U}=\widehat{y}_{U}+\widehat{s}_{L_{U}}-\left(\widehat{w}-\widehat{p}_{U}\right)$, where all terms on the right hand side have been described and quantified above. With zero profits in the competitive unfavored sector, growth in labor's share of revenues is $\widehat{s}_{L_{U}}=\left(1 \widehat{-\alpha}_{U}\right)$, where the unfavored capital share in costs used the EU KLEMS sectoral data. ${ }^{18}$ This gives $\widehat{l}_{U}=$ $6.1+0.0-1.9=4.2$ percent per year. Turning to unfavored capital, an identical procedure generates $\widehat{k}_{U}=6.1$ percent per year. ${ }^{19}$

Finally, turning to the adding-up identities, we need estimates of $\left(L_{F} / L\right)$ and $\left(K_{F} / K\right)$. We start by estimating labor's share of revenue in the favored sector from the implicit relationship: $s_{L}=\omega_{F} s_{L_{F}}+\left(1-\omega_{F}\right) s_{L_{U}}$. We have data on all terms other than $s_{L_{F}}$, so the equation implies that labor's share of revenues in the favored sector is 34 percent. Although this share may seem low, it exactly matches labor's share of value added for U.S. multinationals which, according to U.S. Bureau of Economic Analysis data, was also 34 percent from 1983-1998). Since the wage is assumed identical in the two sectors, we can then use the expression:

$$
\frac{L_{F}}{L_{U}}=\frac{s_{L_{F}}}{s_{L_{U}}} \frac{\omega_{F}}{\omega_{U}}=\frac{0.34}{0.77} \frac{0.59}{0.41}=0.64
$$

which implies that $\left(L_{F} / L\right)=0.39$. Thus, although the favored sector is larger, its low labor intensity implies that the unfavored sector employs more workers. Finally, combining the sectoral shares of the total labor force with the aggregate labor growth estimate in Young (1995), $\widehat{l}=6.2$, implies (from the adding-up identity) that $\widehat{l}_{F}=9.4$ percent.

For capital, the calibration is more complicated, since user costs aren't equated across sectors. We obtain a benchmark by defining the user-cost ratio $\eta=R_{F} / R_{U}<1$, the capital stock ratio $\beta=K_{F} / K_{U}$, and using the relationship:

$$
\eta \beta=\frac{R_{F} K_{F}}{R_{U} K_{U}}=\frac{s_{K_{F}}}{s_{K_{U}}} \frac{\omega_{F}}{\omega_{U}}=\frac{0.24}{0.23} \frac{0.59}{0.41}=1.5
$$

Appendix B details our estimates that $R_{U} / q$ averages about 13.0 percent and $R_{F} / q$ averages about 9.2 percent (reflecting subsidized capital and preferential tax treatment). Thus, $\eta=R_{F} / R_{U}=$ 0.71 , which implies $\beta=2.1$ and $K_{F} / K=\beta /(1+\beta)=0.68$. Given aggregate $\widehat{k}=10.9$ and

\footnotetext{
${ }^{18}$ Given the Cobb-Douglas assumption for one-digit industries, the only reason the unfavored share $s_{L, U}$ would change is if the mix of industries with the unfavored sector changed; such variation is small.

${ }^{19}$ We also now have the information to calculate unfavored technology using the primal. The result is the same as the dual calculation: $6.1-0.81 * 4.2-0.19 * 6.1=1.5$ percent.
} 
$\widehat{k}_{U}=6.1$, we find $\widehat{k}_{F}=\left(\widehat{k}(1+\beta)-\widehat{k}_{U}\right) / \beta=13.1$ percent. $^{20}$

The cost-based primal, (3), now gives favored technology growth, $\widehat{a}_{F}$ :

$$
\begin{aligned}
\widehat{a}_{F} & =\widehat{y}_{F}-\alpha_{F} \widehat{k}_{F}-\left(1-\alpha_{F}\right) \widehat{l}_{F} \\
& =9.6-(0.41)(13.1)-(0.59)(9.4)=-1.3 \text { percent. }
\end{aligned}
$$

Thus, the favored sector was growing nearly 10 percent a year, with falling technology. ${ }^{21}$

In a proximate sense, the negative technological growth reflects the rapid growth in favored inputs, especially capital. Aggregate technology growth is the output-share-weighted sum of technology growth in the two sectors: $\widehat{a}=\omega_{U} \widehat{a}_{U}+\omega_{F} \widehat{a}_{F}$. Column 1 of Table 3 shows that with $\widehat{a}_{F}=-1.3, \widehat{a}_{U}=1.5$, and $\omega_{F}=0.59, \widehat{a}$ is -0.2 percent per year.

Technology growth is only 0.1 percentage point per year stronger than the primal estimate of negative TFP growth. (Our primal TFP figure differs very slightly from Young's original TFP results because of minor differences in aggregate output growth in his vintage of data and ours.) From (7), we know that $\widehat{T F P}$ Primal $-\widehat{a}=s_{\Pi}\left(\widehat{x}_{F}-\widehat{k}\right)+\Sigma_{K}$, and we can use the above calculations to verify that $s_{\Pi}\left(\widehat{x}_{F}-\widehat{k}\right)$ is negligibly small-both cost-weighted favored inputs and aggregate capital were rising at about 10.9 percent per year. $\Sigma_{K}$ is about $-0.1 .^{22}$ Despite the massive scale of the distortions in Singapore's economy, including a 30 percent gap in favored and unfavored user costs with large differences in growth rates between favored and unfavored capital, the dynamics of these distortion terms do not contribute much to the long-term evolution of aggregate TFP growth. Loosely speaking, the reallocation terms are second-order - they involve the product of differences in growth rates and differences in user costs, which tends to make them small.

For our baseline case in Singapore, the standard Solow residual thus turns out to be a close approximation to technology change, at least when averaged over a period of several decades. Interestingly, using an aggregate cost-based residual — weighting labor with its aggregate cost share of 0.68 and capital with its cost share of 0.32 - would yield positive TFP growth of 0.5 percent

\footnotetext{
${ }^{20}$ The log change in $R K$ can be written as: $(\widehat{R K})=\psi\left(\widehat{R U K}_{U}\right)+(1-\psi)\left(\widehat{R F}_{F}\right)$, where $\psi=1 /(1+\eta \beta)$. This equation can also be solved for $\eta \beta$, and does not yield the same value as (9) - our calibration is, loosely speaking, overidentified. But the two estimates are in fact quite close - they take values of 1.5 (in text) and 1.3 (in footnote). In essence, our story is not consistent with any arbitrary sectoral definitions. Placing manufacturing in the unfavored sector, for example, would yield a dramatically larger discrepancy between these value. Our allocation relied on qualitative evidence alone and allocates each industry entirely into one sector or the other, so the small difference corroborates our calibration.

${ }^{21}$ Young (1994) finds that TFP growth fell even more in manufacturing (where he is able to estimate inputs) than in the overall economy, consistent with these estimates.$$
{ }^{22} \Sigma_{K}=\left[\left(K_{F} / K\right)\left(K_{U} / K\right)(R K / P Y)\right]\left(\left(R_{F}-R_{U}\right) / R\right)\left(\widehat{k}_{F}-\widehat{k}_{U}\right)=0.68 \cdot 0.32 \cdot 0.24 \cdot(-0.36) \cdot 0.07=-0.0013 .
$$ 
per year, which would provide a less accurate view of technology growth. The reason is that with the dual formulation, the reallocation terms are much larger in magnitude. The capital reallocation term, $\left(1-s_{\Pi}\right)^{-1} \Sigma_{K}$, is -0.2 percent per year; but the "profits reallocation" term $\left(s_{\Pi}\left(1-\omega_{F}\right) /\left(1-s_{\Pi}\right)\right)\left(\widehat{x}_{F}-\widehat{x}_{U}\right)$ is 0.8 percent. Hence, it would be misleading in Singapore's case to attempt to simply adjust the aggregate shares - it is more accurate to use the "incorrect" $s_{L}$ and $\left(1-s_{L}\right)$.

What key assumptions and features of the data drive these estimates? In the unfavored sector, perfect competition, constant returns, and the lack of unobserved capital subsidies are crucial, since they allow us to use the dual approach. The assumption of unfavored constant returns is reasonable, given standard "replicability" arguments for competitive sectors; and the anecdotal evidence of capital subsidies focuses almost entirely on a few domestic sectors and sectors receiving large amounts of foreign investment. Together, this set of assumptions imply modest growth rates of inputs in the unfavored sector. This is likely to be robust finding: unfavored technology growth is positive, which implies that favored input growth, $\widehat{x_{U}}$, has to be weaker than the already moderate growth in favored output.

Conversely, the poor technology performance in the favored sector is also likely to be robust. Modest unfavored input-growth estimates along with relatively fast overall input growth implies that favored inputs must have grown rapidly. These, in turn, drive the weak technology performance in the sector and overall.

Given the underlying forces in the data that drive the estimates, our quantitative and qualitative results are not particularly sensitive to the assumptions we have made. Table 3 demonstrates the robustness by relaxing several of the assumptions. For example, as mentioned above, our baseline drops the ROE data - one of Hsieh's three interest-rate measures - for the unfavored cost of capital. Column 2 shows that including the ROE user-cost measure reduces $\widehat{a}_{U}$ negligibly, since the capitalweight is small; it slightly improves $\widehat{a}_{F}$ (because it raises $\widehat{k}_{U}$ and thereby reduces $\widehat{k}_{F}$ ). Column 3 substantially increases the mean ratio of favored to unfavored capital $\left(K_{F} / K_{U}\right)$; this necessarily reduces favored capital's growth rate $\left(\widehat{k}_{F}\right)$, but only slightly improves favored technology $\left(\widehat{a}_{F}\right)$. Our results are also robust to arbitrary reductions of the estimated profit shares. Columns 4 and 5 show results from two different experiments that each roughly halve the average profit share. In the first, we increase the industry capital shares (relative to the EU KLEMS estimates) by 9 percentage points in each sector, while in the second, we increasing the growth accounting labor share by 8 percentage points each year. In both of these cases, the baseline results do not change significantly. 


\subsection{Interpreting Negative Technology Growth}

Persistently negative technological progress in the favored sector is surprising. The issue is that, although output rose rapidly, observed inputs rose even faster. It is not simply a matter of weights on capital and labor, since both factors rose faster than favored output.

Perhaps the most straightforward case for a negative residual is if favored returns to scale were decreasing rather than constant. In measuring favored inputs, we assumed constant returns in the unfavored sector but imposed no such assumption for the favored sector. Industry estimates for other countries generally suggest constant or slightly increasing returns (e.g., Basu and Fernald, 2001, and Inklaar, 2007), making constant returns the right benchmark. However, government interventions that limit entry could lead to decreasing returns by causing firms to each overproduce, thereby reducing the economy's efficiency. Consider a simple example. Suppose production requires a fixed cost $F$ and entails an increasing marginal cost: $Y=X^{\lambda}-F$, where $X$ is a composite input, $\lambda<1$, and $\gamma=d \ln Y / d \ln X=\lambda(1+F / Y)$ denotes returns to scale (so $\gamma<1$ implies decreasing returns). The competitive equilibrium, where $M C=A C$, has constant returns to scale $(\gamma=1)$. Government-supported entry barriers shift the firm's demand curve up as well as making it less elastic. If the upward shift dominates the reduced elasticity, then each firm produces more, which pushes $\gamma<1$. Subsidies to input use also lead firms to overproduce and push down $\gamma$. In either case, the firm's average cost exceeds its minimum value, so that the government interventions reduce the efficiency of the economy even if true technology does not change. ${ }^{23}$ Hence, Singapore's heavy interventions could have led to a falling cost-based TFP residual (and, therefore, reduced our measured technology) - even if it favored high-productivity firms. Under this interpretation, the qualitative conclusion remains that Singapore's growth was not driven by efficiency improvements.

Alternatively, the economy may have shifted "too rapidly" into new products and industries, as Young (1992) suggests. If there is an important role for learning-by-doing, as well as up-front adoption costs, then shifting rapidly means that Singapore could have paid a lot of adoption costs without reaping all the benefits. ${ }^{24}$ Further, if government favoritism chose the wrong sectors, the rapid gains in output might have reflected high input growth that more than offset the negative technology growth, consistent with the decline in measured economic profits. In a sense, this implies

\footnotetext{
${ }^{23}$ Similarly, Restuccia and Rogerson (2004) offer a story in which firms have decreasing returns (e.g., from limited managerial span of control) but differ in productivity levels. Shifting resources away from the undistorted equilibrium - whether towards or away from high-productivity firms - reduces overall TFP and welfare.

${ }^{24}$ Young's hypothesis would imply that Singapore adopted new technologies more rapidly than Hong Kong. But, for electronic goods such as cell phones and personal computers, Comin and Hobijn (2010) find no evidence that Singapore in fact adopted them more rapidly.
} 
that the negative reallocation effect we derived when looking across the favored and unfavored sectors might have additionally mattered within the favored sector itself, or even internal to large favored firms. After all, our "favored sector" is a fairly crude mapping from one-digit industries, and it is certainly not homogeneous (e.g., finance is very different from utilities).

In sum, it remains unclear what factors drove the extremely slow technology growth in Singapore, though these may include decreasing returns, within-sector reallocation effects (the equivalent of the between-sector effects we measure), and could to some extent also reflect mismeasurement (for example, we do not try to reconcile differences in estimates of Singapore's wage growth). It could be that the same policies which resulted in Singapore's poor productivity performance also led to its rapid output growth. A virtue of our measurement framework is that it makes the minimal set of assumptions necessary for estimating technology growth as distinct from TFP growth, but it does not allow us to perform counterfactuals. A fully-specified dynamic general equilibrium growth model is likely needed to explore more fully how policy affected Singapore's growth experience. ${ }^{25}$

\section{Reconciling Empirical Puzzles Regarding Growth in Asia}

Finally, we apply our framework and quantification of market imperfections to reconcile empirical puzzles related to the rapid development of the NIEs. We start with the gap between dual and primal TFP in Singapore and then discuss the lack of gap for other NIEs. We then note how our quantification of profit shares in the NIEs reconciles a key implication of trade-based explanations of Asia's rapid development that previously contradicted the data.

\subsection{Understanding Gaps in Singapore's TFP Growth Calculations}

Our estimates of Singapore's market imperfections quantitatively reconciles the gap between Hsieh's dual and Young's primal TFP results. Manipulating equation (6) for the aggregate economy, the difference between typical implementations of the dual and primal is:

$$
\widehat{T F P}_{\text {Dual }}-\widehat{T F P}_{\text {Primal }}=s_{L}\left(\widehat{w}_{\text {Dual }}-\widehat{w}\right)+\left(1-s_{L}\right)\left(\widehat{r}_{\text {Dual }}-(r+\pi / k)\right)
$$

\footnotetext{
${ }^{25}$ If technology growth were so poor, then the level of technology itself ought to be relatively low. Bar-Shira et al (2003) use a method very different from ours to estimate levels of technology across countries. In a cross-sectional sample of 25 countries for 1990, Singapore ranked dead last in the level of technology-not only below all of the other NIEs, but below many other countries that had lower output per capita.
} 
If both use the same weights, then primal and dual TFP growth differ only if growth in either estimated wages or capital-payments differ (given the distortions discussed above, neither measures economy-wide technology growth).

Table 4 gives this decomposition for all the NIEs with data from Young $(1995,1998)$ and Hsieh (2002). Lines 1 to 3 show the items on the right side of equation (10). Notably, line 2a shows that Young's estimates imply that real capital payments, $(r \widehat{+\pi} / k)$, fell at 3 percent per year, whereas Hsieh's dual estimate $\widehat{r}_{\text {Dual }}$ was roughly constant (rising by 0.4 percent per year). Lines $4 \mathrm{a}$ and $4 \mathrm{~b}$ show primal and dual TFP growth. Lines 5 and 6, respectively, show the contribution of wages and capital payments to the dual-primal difference. Primal and dual TFP growth differed markedly only in Singapore and Taiwan. Wages play a sizeable role in Singapore and account for the bulk of the difference in Taiwan. Hsieh (2002) has little discussion of the role of wages. ${ }^{26}$ The wage discrepancies reflect measurement rather than conceptual differences.

The theoretical framework of Section 2 can explain capital's contribution (line 6, which shows the second term in (10)). In Singapore, this term accounts for the bulk of the dual-primal gap: The weak primal TFP performance implies sharp declines in real capital payments, $(r+\widehat{+\pi} / k)$, but estimated user costs are about flat. The issue, then, is to reconcile line 2a (the sharp decline in $(r \widehat{+\pi} / k))$ with line $2 \mathrm{~b}$ (the flat or even slightly rising $\left.\widehat{r}_{D u a l}\right)$.

Can the unrepresentativeness of $\widehat{r}_{\text {Dual }}$ as well as pure economic profits quantitatively reconcile these two estimates? With some algebraic manipulation, we can write:

$$
(r \widehat{+\pi} / k)=\widehat{r}+\frac{s_{\Pi}}{1-s_{L}}\left(\widehat{s}_{\Pi}-\widehat{s}_{K}\right) .
$$

Capital payments can change either because the "average" user cost, $\widehat{r}$, changes, or because there are pure profits and the profit rate changes relative to capital's share of output. Intuitively, suppose the user cost is constant. Then any changes in capital's share are driven by changes in capital relative to output. Thus, after stripping out growth in the user cost, the term $\pi / k$ will increase if and only if growth of profit share exceeds that of capital share.

\footnotetext{
${ }^{26}$ The two use different source data on wages and employment. With $J$ types of labor, Young measures $\widehat{l}=\sum s_{j} \widehat{l_{j}}$. He benchmarks to total labor compensation, which imposes the identity that $W L=\sum W_{j} L_{j}$. Hence, his estimate of implicit real wage growth, $\widehat{w}_{\text {Primal }}-\widehat{p}=\widehat{s_{L}}+\widehat{y}-\widehat{l}$, is necessarily consistent with the aggregate compensation figures. Hsieh measures $\widehat{w}_{\text {Dual }}=\sum s_{j} \widehat{w}_{j}$ directly, so he doesn't need to benchmark to aggregate compensation. Implicitly, two factors "explain" the wage differences. First, Hsieh's survey data have less growth in employment than the official tabulations and he has less implied labor quality growth than Young (1995); for given growth in nominal compensation, these factors imply faster wage growth. Second, Hsieh's figures on total labor compensation rise from 25 percent of GDP in 1973 to 37 percent of GDP in 1990. Hence, he has faster growth in nominal labor compensation. Young (1998) questions the reliability of Hsieh's wage data.
} 
What does the aggregate user cost, $\widehat{r}$, depend on? Since $R \equiv\left(K_{F} / K\right) R_{F}+\left(K_{U} / K\right) R_{U}$ :

$$
\widehat{r}=\frac{R_{F} K_{F}}{R K} \widehat{r}_{F}+\frac{R_{U} K_{U}}{R K} \widehat{r}_{U}+\frac{R_{F}-R_{U}}{R} \frac{K_{F}}{K}\left(\widehat{k}_{F}-\widehat{k}\right)
$$

Growth in the aggregate user cost is a weighted average of growth in the user cost in the two sectors, plus a reallocation term reflecting that average $R$ can fall if we capital shifts towards a sector with a lower value of $R$. Hsieh's dual did not incorporate any tax adjustments, so $\widehat{r}_{U}=\widehat{r}_{D u a l}+\widehat{t}_{U}$. We additionally substitute in $\widehat{r}_{F}=\widehat{r}_{U}+\left(\widehat{t}_{F}-\widehat{t}_{U}\right)$ to write:

$$
\widehat{r}=\widehat{r}_{D u a l}+\operatorname{tax}+\frac{R_{F}-R_{U}}{R} \frac{K_{F}}{K}\left(\widehat{k}_{F}-\widehat{k}\right)
$$

where $\operatorname{tax}=\left(R_{F} K_{F} / R K\right) \widehat{t}_{F}+\left(R_{U} K_{U} / R K\right) \widehat{t}_{U}$ is the share-weighted average of growth in taxes in the two sectors. From the tax code (see Appendix B), we can observe some portion of the tax terms but, obviously, not unobserved subsidies to favored firms. Let $\widehat{t}_{F}=\widehat{t}_{F}^{o b s}+\varepsilon$, where $\varepsilon$ reflects the effects of unobserved subsidies, so that we can analogously write $\operatorname{tax}=\operatorname{tax}^{\mathrm{Obs}}+\left(R_{F} K_{F} / R K\right) \varepsilon$. Then:

$$
\widehat{r}=\widehat{r}_{\text {Dual }}+\operatorname{tax}^{\mathrm{Obs}}+\frac{R_{F}-R_{U}}{R} \frac{K_{F}}{K}\left(\widehat{k}_{F}-\widehat{k}\right)+\frac{R_{F} K_{F}}{R K} \varepsilon
$$

Combining this expression with (11), we have:

$$
(r \widehat{+\pi} / k)+\widehat{r}_{D u a l}+\operatorname{tax}^{O b s}+\frac{R_{F}-R_{U}}{R} \frac{K_{F}}{K}\left(\widehat{k}_{F}-\widehat{k}\right)+\frac{s_{\Pi}}{1-s_{L}}\left(\widehat{s}_{\Pi}-\widehat{s}_{K}\right)+\frac{R_{F} K_{F}}{R K} \varepsilon
$$

Growth in payments to capital implied by the primal can differ from the dual estimate because of changes in the share-weighted growth in observed tax wedges, because of a reallocation of capital towards sectors with different levels of the user cost, because of profits, or because of unobserved subsidies.

We have already discussed many of these terms, and Table 5 shows our decomposition of the gap into each of them. Line (1) shows Hsieh's $\widehat{r}_{\text {Dual }}$ of 0.4 percent per year. Line (2) shows the share-weighted tax-wedge adjustment that we can observe, $\operatorname{tax}^{\mathrm{Obs}}$, fell about 0.9 percent per year. To calculate this adjustment, we use our previous estimate $\widehat{t}_{U}=-0.7$. In addition, we estimate that $\widehat{t}_{F}^{O b s}=-0.9 .^{27}$ Given the assumptions in Section 4.1, $\left(R_{F} K_{F} / R K\right)=\eta \beta /(1+\eta \beta)=0.60$,

\footnotetext{
${ }^{27}$ This figure comes from the data on tax rates for foreign manufacturing from Figure 1B, where we assume that other firms (favored or unfavored) paid the statutory tax rate. An investment allowance introduced in 1980 for some manufacturing firms made the tax code even more advantageous for favored firms. (Appendix B discusses how we
} 
which allows us to calculate the share-weighted observable tax wedge. (Note that rounding matters. Both $\widehat{t}_{U}$ and $\widehat{t}_{F}^{\text {Obs }}$ round down, whereas tax ${ }^{\text {Obs }}$ rounds up. $)^{28}$

Line (3) uses the benchmark estimates from Section 4.1 to obtain the reallocation term: $\left[\left(R_{F}-\right.\right.$ $\left.\left.R_{U}\right) / R\right]\left(K_{F} / K\right)\left(\widehat{k}_{F}-\widehat{k}\right)=[(9.2-13.0) / 10.4](0.68)(13.1-10.9)=-0.5$ percent per year. Line (4) uses the values from Table 2 (the second column, corresponding to our preferred two-sector breakdown) for the pieces of the profits term, $\left[s_{\Pi} /\left(1-s_{L}\right)\right]\left[\widehat{s}_{\Pi}-\widehat{s}_{K}\right]$.

In principal, if there were no unobserved capital subsidies or mismeasurement, then the sum of lines (1) through (4) would equal the primal estimate in line $(6)$ of $(r+\pi / k)=-3.0$ percent. However, line (5) shows that there is a residual of 0.6 percent per year that is not yet accounted for. In principal, that residual reflects unobserved capital subsidies. There is surely further unobserved heterogeneity in user costs — such as favorable access to land and financing - that accounts for some if not all of this residual. In any case, the terms in our framework that we can measure explain the bulk of the gap between the primal and dual estimates of payments to capital. (Of course, that residual term could also capture some mismeasurement.)

This reconciliation of Hsieh's dual with Young's primal calculation requires that Hsieh's cost of capital measure captures the user cost for the unfavored sector only and excludes profits. Why is this a reasonable assumption? Hsieh uses three rate-of-return measures for Singapore's dual calculation: The earnings-to-price ratio $(\mathrm{E} / \mathrm{P})$; an average lending rate; and the return on equity (ROE). All omit subsidies and taxes, and two of the three omit profits.

First, consider the earnings-price ratio as a measure of the expected real return $(\rho-\widehat{q})$. With perfect capital mobility, this measure is, at best, the expected real return for the global representative investor. Such a rate might be appropriate for a firm seeking private-sector financing (which, presumably, many companies receiving preferential treatment did not need). But even if the listed firm earned large pure profits, this raises prices as well as earnings. ${ }^{29}$

implement these and other adjustments from the tax code in order to calculate the favored tax wedge.)

${ }^{28}$ Although the decline in statutory rates was smaller than the decline in foreign manufacturing rates, the decline in $T_{i}$ was still large for firms outside foreign manufacturing because of the increase in $D$. Note also that the declining tax wedge is consistent with a rising corporate tax-to-GDP ratio because (corporate profits/GDP) was rising.

${ }^{29}$ There appears to be a long history in securities analysis of using the earnings-price ratio as an empirical measure of the real discount rate, $\rho-\widehat{p}$, where $\widehat{p}$ is a price deflator. A standard formula (e.g., Brealey and Myers, 2000, p73) says that a company's share price is $P_{i}=E_{i} /(\rho-\widehat{p})+P V G O_{i}$ - the value of a perpetuity yielding $E_{i}$, plus the present value of growth opportunities. (The general point, of course, is that price is the present value of the stream of dividends from the stock; but it can be useful to decompose it into a "no growth" valuation, and a separate valuation of the growth opportunities). The equation implies that $E_{i} / P_{i}=(\rho-\widehat{p})\left(1-P V G O_{i} / P_{i}\right)$. In applying this equation to aggregate stock-market data, Hsieh implicitly assumes that $P V G O_{i}=0$. An additional, potential, complication is that $\widehat{p}$ might differ from growth in the investment deflator, $\widehat{q}$, which is what enters the user-cost formula. This consideration is minor for Singapore where, from 1960-95, the investment deflator grew at about the same rate as the GDP deflator (structures prices grew more quickly, equipment prices more slowly). 
Second, the average bank lending rate is also more appropriate for unfavored firms. Young (1998) describes how a heavily regulated "cartel arrangement" kept lending rates above competitive levels. But GLCs, SBs, and multinationals generally had alternative, likely cheaper sources of funding, including government loans, FDI, and international lending. In the 1980s, for example, only 21 percent of Singapore bank loans to non-bank customers went to heavily favored manufacturing, transport, and communications industries - which accounted for 40 percent of GDP. FDI was a much more important funding source for these firms. In addition, firm-level profits would not have any direct effect on average lending rates.

Finally, the return on equity (ROE, from Singapore's Registry of Companies and Businesses) is the ratio of two easily manipulated elements in firm financial statements - it is an accounting, not a market, measure. Consider the denominator. Firms have considerable discretion in reporting intangible assets such as goodwill or brand name, which affects the book value of shareholder equity; firms earning large profits seem particularly likely to report sizeable intangible assets. From 198090, the underlying asset figures for non-financial firms alone show a ratio to GDP that averages 4.5 - compared with a capital-output ratio of 2.8 in the national accounts.

In sum, the ROE figures are not a reliable measure of the opportunity cost of funds. Indeed, if we omit the ROE measure (as, in fact, we did in measuring technology in Section 4), then the real dual estimate of $\widehat{r}_{D}$ falls to +0.2 percent per year. This would reduce the primal-dual discrepancy (line 5 of Table 5 ) by 0.2 percentage points. ${ }^{30}$

Our interpretation of the dual-primal divergence is more plausible than the main alternatives. First, Hsieh suggests, with little evidence, that there were massive national accounting errors. In particular, the national accounts might have massively overstated growth in the capital-output ratio, either by understating output growth or overstating capital growth. We discuss this hypothesis (and its difficulties) in Appendix C. Second, Young dismisses the dual calculations, in part because they ignore key tax benefits and are not appropriate for all firms. We agree that these issues are central, but find the pattern of mismeasurement economically important. The primal and dual methods differ because a subset of the economy earned very large and declining profits and received government favoritism that grew over time. ${ }^{31}$

\footnotetext{
${ }^{30}$ Since Section 4 omitted the ROE figure, lines (2) through (4) of Table 5 are unaffected. Instead, this modification would reduce the residual in line (5) from 0.6 to 0.4 - plausibly explained by land subsidies or other (growing) capital subsidies.

${ }^{31}$ See also Feenstra and Reinsdorf (2003) and Barro (1999) for additional possible interpretations of the dual-primal discrepancy and the implications for national accounts.
} 


\subsection{Why the Dual and Primal Calculations are Consistent in the Other NIEs}

In Singapore, large but declining profits and heterogeneous costs of capital, reflecting government intervention, created the large dual-primal TFP gap. How did these factors play out in the other NIEs? Tax effects were smaller outside of Singapore; and profits and unmeasured subsidies appear relatively unimportant in less-interventionist Hong Kong. But Taiwan and Korea also intervened heavily. Why is the gap so much smaller in Taiwan? Why isn't there a gap in Korea?

For Taiwan, Wade (1990) documents the considerable government intervention, especially for large firms in favored sectors. Government intervention, however, does not inevitably lead to high profits - Singapore is the exception to world experience, not the rule. Estimated profits in Taiwan were small. ${ }^{32}$ Hence, capital's contribution to Taiwan's dual-primal gap is consistent with unmeasured, heterogeneous, capital subsidies creating a modest gap.

Korea also intervened, but the evidence suggests it did so without creating large profits or heterogeneity in the growth rates of the cost of capital. First, our estimates, as well as Leipziger's (1988) and Kihwan and Leipziger's (1997) firm-level studies, suggest small profits. Second, Hsieh reports different levels of the user cost using the curb loan rate (the market rate) and the discount rate (the "preferred" rate); but they move roughly in parallel. ${ }^{33}$

In addition, while FDI played a huge role in Singapore's development, it had negligible impact on Korea in the 1970's and 1980's. IFS statistics confirm that by 1990, FDI amounted to nearly half of investment in Singapore but only 1 percent of investment in Korea. As such, the idiosyncratic, one-time benefits offered to entice FDI and leading to large profits and subsidies in Singapore had less scope to impact growth accounting in Korea.

Finally, we find direct evidence that wedges in the cost of capital due to tax treatment were far less important in the other NIEs. Table 6 shows that the equivalent tax adjustments (the first term from (13)) for the other NIEs appear much smaller than in Singapore. For Taiwan, the -0.9 percentage point per year contribution largely reflected increases in investment tax credits $(\kappa)$ in the 1980s. In Korea, tax rates for large companies fell over time, and depreciation allowances became somewhat more generous. But $\kappa$ (for selected investments) also became less generous. In Hong Kong, the change in the tax wedge contributes nothing to the dual-primal gap: depreciation allowances became slightly more generous over time, but the corporate tax rate also rose slightly.

\footnotetext{
${ }^{32}$ For Taiwan, Hong Kong, and Korea, the estimated contribution of profits from equation (13) is small.

${ }^{33}$ Heterogeneity can also reflect differences in user-cost levels, but differing growth rates are a more direct source. Rhee (1997) discusses the dual structure of Korea's financial market.
} 
The second line multiplies these tax correction terms by $-\left(1-s_{L}\right)$ to show the contribution of the observable tax correction term to the overall dual-primal gap in measured TFP growth.

In sum, there are many similarities in the broad development strategies of Singapore, Taiwan, and Korea. But the lack of profits and similar growth rates in favored and unfavored costs of capital, even when taking into account tax treatment, resulted in relatively consistent dual and primal TFP estimates outside of Singapore.

\subsection{The Role of Trade and Export-Led Growth}

Theories that stress the role of international trade in Asian growth predict rising capital shares and falling labor shares. Romalis (2004) finds that as the NIEs accumulated human and physical capital, their share of world production and exports of capital-intensive goods rose and their share of unskilled-labor-intensive production fell, implying capital's share of costs rose. Ventura (1997) extends a form of the factor-price-equalization theorem, and shows how small open economies can sustain rapid growth without diminishing factor returns. In essence, trade in goods is an indirect way to trade factors of production, which have diminishing returns only globally. Shifting production toward an export sector intensive in a given factor need not imply a rapid decline in that factor's returns, so long as such exports replace use of that factor abroad. ${ }^{34}$ Since the NIEs accumulated capital far faster than skill-adjusted labor, Ventura's explanation also implies rising capital shares and falling labor shares. ${ }^{35}$

We showed in line 2 of Table 2 , however, that $\left(1-s_{L}\right)$ fell over time in 3 of the 4 NIEs inconsistent with Ventura's predictions and surprising given Romalis's results. But "true" capital shares in cost increased over time $(\widehat{\alpha}$, line 4$)$ in 3 of the 4 . Hence, in addition to reconciling disparities between the dual and primal growth accounting results, our approach also resolves inconsistencies between the data and key predictions of the international trade literature.

\section{Conclusion}

We derive aggregate growth accounting implications for a two-sector economy with two empirically prevalent distortions: heterogeneous capital subsidies and monopoly power. In this economy, measures of primal and dual TFP growth can diverge from each other and from true technology

\footnotetext{
${ }^{34}$ Under certain conditions, Ventura's factor-price equalization results imply truly constant factor prices. But his explanation remains valid as long as factor prices decline at slower rates than factors are accumulated.

${ }^{35}$ Ventura's predictions for factor shares are relative to the rest of the world. In BLS or Jorgenson data for the United States, there is little evidence of a trend in factor shares over this period.
} 
growth. Further, measurement of aggregate growth in this environment reflects reallocation effects that are the dynamic counterpart of the levels effects discussed in the misallocation literature.

We discuss the case study of Singapore in more detail to illustrate some of the ways these distortions manifest themselves. In such an economy, technology needs to be measured from the bottom up, requiring data that aren't easily available. But we show how partial and incomplete data can be combined to measure technology and sectoral dynamics. The main empirical finding is that in Singapore, aggregate technology growth during the fastest growth decades of the 1970s and 1980s was slightly negative. Indeed, in the "favored" sector, where output grew nearly 10 percent per year for this period, technology growth was sharply negative. Productivity growth is sometimes defined loosely as the ability to do more with less. In this sense, Singapore instead achieved less with more!

In addition, our estimates resolve two important empirical puzzles regarding Asian development. First, we quantitatively reconcile divergent estimates of TFP growth from the dual and primal sides. Unmeasured heterogeneity in the cost-of-capital (reflecting intentional programs to direct resources to particular firms and/or sectors) and large but declining pure economic profits explain much of the dual-primal gap. Second, we reconcile the constant or increasing labor shares in revenue with the intuitive story that rapid Asian growth relied heavily on a shift towards capital-intensive export sectors. The declining profit share allowed labor's share to remain flat or even rise despite a shift (which we document) towards capital-intensive sectors.

Our detailed examination of the NIEs provides both important caveats to, and new applications of, primal and dual growth accounting. When undertaking growth accounting for a country or across countries, there is value in carefully constructing both primal and dual measures because they are sensitive to different distortions. Resolving discrepancies can shed light on the underlying structure of the economy, in addition to providing insight into possible mismeasurement. Thus, this paper reinforces the message of a growing body of empirical and theoretical work that recommends looking inside the black box of aggregate growth accounting.

Our approach focuses on empirically relevant conditions in which, because of distortions, measured TFP diverges from technology. Our approach does not require us to specify the entire economic environment, since it takes equilibrium allocations as observed outcomes, and then interprets them with first-order conditions that would apply in many economic environments. However, it is important to recognize that technology change is not the same thing as welfare change. To the extent that Singapore grew rapidly — with rapid growth in consumption possibilities - because 
of its interventions, it could well have raised the welfare of its citizens. ${ }^{36}$ Understanding how the interventions affected growth in GDP, TFP, technology, and welfare is beyond the scope of this paper, and requires a fully-specified multi-sector dynamic general equilibrium model that incorporates realistic distortions (such as government subsidies).

\footnotetext{
${ }^{36}$ Basu and Fernald (2002) discuss links between productivity residuals and welfare.
} 


\section{References}

[1] Auerbach, Alan (1983). "Taxation, Corporate Financial Policy and the Cost of Capital." Journal of Economic Literature, September 1983, 905-940.

[2] Asher, Mukul (1989). "Fiscal System and Practices in Singapore." In M. Asher, Ed., Fiscal systems and practices in ASEAN : trends, impact and evaluation. Pasia Panjang, Singapore.

[3] Banerjee, Abhijit V. and Benjamin Moll (2010). "Why Does Misallocation Persist?" Forthcoming, American Economic Journal: Macroeconomics.

[4] Bar-Shira, Ziv, Israel Finkelstein and Avi Simhon. (2003). "Cross-Country Productivity Comparisons:

The Revealed Superiority Approach," Journal of Economic Growth 8 (3): 301-323.

\section{References}

[1] Basu, Susanto and John G. Fernald (2001). "Why Is Productivity Procyclical? Why Do We Care?" In New Directions in Productivity Analysis, edited by Edwin Dean, Michael Harper and Charles Hulten. (Studies in Income and Wealth Volume 63). University of Chicago Press.

[2] Basu, Susanto and John G. Fernald (2002). "Aggregate productivity and aggregate technology," European Economic Review, Elsevier, vol. 46(6), pages 963-991, June.

[3] Blanchard, Olivier and Francesco Giavazzi (2003). "The Macroeconomic Effects of Regulation and Deregulation in Goods and Labor Markets." Quarterly Journal of Economics, 118-3, pp879909.

[4] Barro, Robert (1999). "Notes on Growth Accounting." Journal of Economic Growth Vol 4, No. 2, pp 119-137.

[5] Brealey, Richard A. and Stewart C. Myers (2000). Principles of Corporate Finance. Sixth edition. New York: McGraw Hill.

[6] Burton, John (2002). "Doubts grow about the value of state businesses," Financial Times. April 12.

[7] Chou, Ji and De-min Wu (1994). "The Cost of Capital and the Effective Tax Rate in Taiwan, 1961-1985". In Musgrave, Richard A., Ching-huei Chang, and John Riew, eds., Taxation and Economic Development Among Pacific Asian Countries. Westview Press, Boulder, pp. 117-139.

[8] Comin, Diego and Bart Hobijn (Forthcoming). "An Exploration of Technology Diffusion." American Economic Review.

[9] Corrado, Carol, Charles Hulten, and Daniel Sichel (2004). "Measuring Capital and Technology: An Expanded Framework." Federal Reserve Board Working Paper.

[10] Department of Statistics, Singapore (1992a). "Efficiency of Singaporean Companies: A Study of the Returns to Asset Ratios." Occasional paper on financial statistics. June.

[11] Department of Statistics, Singapore (1992b). Singapore's Corporate Sector 1980-1989. 
[12] Department of Statistics, Singapore (1993). "Profile of Self-Employed Persons in Singapore." Occasion paper, August.

[13] Department of Statistics, Singapore (1995a). Singapore's Corporate Sector 1986-1995.

[14] Department of Statistics, Singapore (1995b). "Foreign Equity Investment in Singapore, 1992." Occasional paper on financial statistics. March.

[15] Department of Statistics, Singapore (2001). "Contribution of Government-Linked Companies to Gross Domestic Product." Occasional paper on economic statistics. March.

[16] Department of Statistics, Singapore (2003). Spreadsheet emailed by Singapore Statistics on August 6, 2003.

[17] Department of Statistics, Singapore (2006). "Selected Corporate Sector Data." Spreadsheet received via email March 2, 2006.

[18] Desai, Mihir A., C. Fritz Foley, and James R. Hines Jr. (2006) "The Demand for Tax Haven Operations." Journal of Public Economics 90, 3: 513-531.

[19] Economist Intelligence Unit, (1993). Financing Foreign Operation: Singapore, September.

[20] Economist (2001). "Ports in a storm," April 12.

[21] Economist (2002). "Whither Singapore Inc.," November 28.

[22] Ermisch, J.F. and W.G. Huff (1999). "Hypergrowth in an East Asian NIC: Public Policy and Capital Accumulation in Singapore." World Development, 27:1, pp 21-38.

[23] Feenstra, Robert C. and Marshall Reinsdorf (2003). "Should Exact Index Numbers Have Standard Errors? Theory and Application to Asian Growth." NBER Working Paper No. 10197.

[24] Fordham, Margaret (1992). Tax Incentives for Investment and Expansion. Second edition. Longman, Singapore.

[25] Gollin, Douglas (2002). "Getting Income Shares Right." Journal of Political Economy.

[26] Hall, Robert E. (1990), "Invariance Properties of Solow's Productivity Residual," in P. Diamond (ed.), Growth, Productivity, Unemployment, Cambridge: MIT Press, pp. 71-112.

[27] Hassett, Kevin and Glenn Hubbard (2002). "Tax Policy and Business Investment," Handbook of Public Economics, vol 3, Alan J. Auerbach and Martin Feldstein,, eds.

[28] Heston, Alan, Robert Summers, and Bettina Aten (2002). Penn World Table Version 6.1. Center for International Comparisons at the University of Pennsylvania (CICUP), October 2002. Downloaded November 22, 2004.

[29] Ho, H.C.Y., and L.C. Chau (1988). The Economic System of Hong Kong. Hong Kong: Asian Research Service.

[30] Ho, H.C.Y. (1979) The Fiscal System of Hong Kong. London: Croom Helm Ltd.

[31] Hsieh, Chang-Tai (2002). "What Explains the Industrial Revolution in East Asia? Evidence from Factor Markets." American Economic Review. 
[32] Hsieh, Chang-Tai and Peter J. Klenow (2010). "Misallocation and Manufacturing TFP in China and India." Forthcoming, Quarterly Journal of Economics 124, December 2009.

[33] Hyun, Jin Kwon, Yunhi Won, and Ilho Yoo (2000) "Marginal Effective Tax Rates in Korea: 1960-1998." Manuscript, Korea Institute of Public Finance.

[34] Inklaar, Robert (2007), "Cyclical productivity in Europe and the United States, Evaluating the evidence on returns to scale and input utilization", Economica, 74 pp822-841.

[35] International Monetary Fund (1995). Singapore: A Case Study in Rapid Development." February.

[36] International Monetary Fund (2004). Singapore: Selected Issues.

[37] Jones, Charles I. (2003). "Growth, Capital Shares, and a New Perspective on Production Functions." Berkeley University Manuscript.

[38] Kee, Hiau Looi (2002). "Markups, Returns to Scale, and Productivity: A Case Study of Singapore's Manufacturing Sector.” World Bank Policy Research Working Paper 2857.

[39] Kihwan, Kim and Leipziger, Danny M. (1997). "Korea: A Case of Government-Led Development." In Lessons from East Asia, Leipziger ed. The University of Michigan Press.

[40] Kim, Jong-Il and Lawrence Lau (1994) "The Sources of Economic Growth of the East Asian Newly Industrialized Countries," Journal of the Japanese and International Economies,September, 8(3), 235-271.

[41] Leipziger, Danny M. (1988). "Industrial Restructuring in Korea," World Development, Volume 16.

[42] Low, Linda, Toh Mun Heng, Soon Teck Wong, Tan Kong Yam, and Helen Hughes. Challenge and Response: Thirty Years of the Economic Development Board. Times Academic Press: Singapore.

[43] Lucas, Robert (1993). "Making a Miracle.” Econometrica LXI: 251-272.

[44] O'Mahony, Mary, and Marcel Timmer (2009). "Output, Input and Productivity Measures at the Industry Level: The EU KLEMS Database," The Economic Journal, Volume 119.

[45] Price Waterhouse (various) Corporate taxes, a worldwide summary. Price Waterhouse, New York.

[46] Ramirez, Carlos and Tan Ling Hui (2003). "Singapore Inc. versus the Private Sector: Are Government-Linked Companies Different?" IMF Working Paper WP/03/156.

[47] Rhee, Changyong (1997). "Curb Market Interest Rates in Korea." Korean Social Science Journal, Vol. XXIV, No. 1.

[48] Restuccia, Diego and Richard Rogerson (2007). "Policy Distortions and Aggregate Productivity with Heterogeneous Plants." NBER Working Paper.

[49] Romalis, John (2004). "Factor Proportions and the Structure of Commodity Trade," American Economic Review. March. 
[50] Rotemberg, Julio J. and Michael Woodford (1995). "Dynamic General Equilibrium Models with Imperfectly Competitive Product Markets." In Thomas F. Cooley, ed., Frontiers of Business Cycle Research. Princeton: Princeton University Press.

[51] Sala-i-Martin, Xavier Gernot Doppelhofer, and Ronald I. Miller (2004). "Determinants of Long-Term Growth: A Bayesian Averaging of Classical Estimates (BACE) Approach." American Economic Review, 94 (4): 813-835.

[52] Senkuttuvan, Arun (1975). "A juicier carrot for foreign investors," Far Eastern Economic Review. August.

[53] Sarel, Michael (1997). "Growth and Productivity in ASEAN Countries." IMF Working Paper, August.

[54] Singapore. Economic Committee (1986). "The Singapore economy: New directions." Report of the Economic Committee, Ministry of Trade \& Industry. (microform)

[55] Tan, Sook Yee (2001). Principles of Singapore Land Law. 2nd ed. Butterworths Asia, Singapore.

[56] Tanzi, Vito and Parthasarathi Shome (1992). "The Role of Taxation in the Development of East Asian Economies." In Takatoshi Ito and Anne O. Kreuger, eds., The Political Economy of Tax Reform. University of Chicago, Chicago, pp. 31-65.

[57] United Nations (1979, 1984). Statistical Yearbook for Asia and the Pacific. Economic and Social commission for Asia and the Pacific, 1979 and 1984 volumes.

[58] U.S. Embassy (2001). "Singapore: Government-Linked Corporations Face the Future." March.

[59] Ventura, Jaume (1997). "Growth and Interdependence." Quarterly Journal of Economics (February): $57-84$.

[60] Wade, Robert (1990). Economic Theory and the Role of Government in East Asian Industrialization. Princeton: Princeton University Press.

[61] Young, Alwyn (1992). "A Tale of Two Cities: Factor Accumulation and Technical Change in Hong Kong and Singapore." In Olivier J. Blanchard and Stanley Fischer, eds., NBER Macroeconomics Annual 1992. Cambridge, MA: MIT Press.

[62] Young, Alwyn (1994). "Lessons from the East Asian NICs: A Contrarian View." European Economic Review 38: 964-973.

[63] Young, Alwyn (1995). "The Tyranny of Numbers: Confronting the Statistical Realities of the East Asian Growth Experience." Quarterly Journal of Economics. (August): 641-680.

[64] Young, Alwyn (1998). "Alternative Estimates of Productivity Growth in the NIC's: A Comment on the Findings of Chang-Tai Hsieh." NBER Working Paper No. 6657 .

[65] Young, Alwyn (2003). "Gold into Base Metals: Productivity Growth in the People's Republic of China during the Reform Period." Journal of Political Economy, Vol 111, no. 6: 1220-1261 (December). 


\section{Tables}

Table 1: Asian Growth Estimates

(Percent per year)

\begin{tabular}{lcccc}
\hline & $\begin{array}{c}\text { PPP-Adjusted } \\
\text { Output Growth } \\
\text { per Capita } \\
(1960-1996)\end{array}$ & $\begin{array}{c}\text { Real Output } \\
\text { Growth } \\
(1970-1990)\end{array}$ & Primal Estimates & Dual Estimates \\
\hline Singapore & 5.6 & $(2)$ & $(3)$ & $(4)$ \\
Taiwan & 6.7 & 8.1 & -0.5 & 1.8 \\
Korea & 6.4 & 8.8 & 2.1 & 3.7 \\
Hong Kong & 5.8 & 9.5 & 1.7 & 1.9 \\
\hline \multicolumn{1}{c}{ Unweighted } & 6.1 & 7.5 & 2.3 & 2.3 \\
\hline \multicolumn{1}{c}{ Average } & & 8.5 & 1.4 & 2.4 \\
\hline
\end{tabular}

Notes: Column (1) is average annual log-change in "rgdpch" from Heston, Summers, and Aten (2002). Columns (2) and (3) are from Young (1998) for Singapore and Young (1995) for Taiwan, Hong Kong, and Korea. For Taiwan, data exclude agriculture and include Young's adjustment of public sector output. Column (4) is from Hsieh (2002). For each economy, Hsieh offers three or four different measures of TFP based on different measures of the real user cost; column (4) shows the average. Each measure is available for slightly different time periods; all measures approximately cover 1970 - 1990. In columns (2) and (3), we give the (weighted) averages across sub-periods of Young's primal TFP to match the time periods for Hsieh's dual TFP. Numbers may not add up due to rounding. Column (2) covers 1971-1991 for Hong Kong. 
Table 2: Estimation of Capital and Profit Shares,1970-1990

(Except where indicated, all entries are percent per year)

\begin{tabular}{|c|c|c|c|c|c|c|}
\hline & & \multicolumn{2}{|c|}{ Singapore } & Taiwan & Korea & Hong Kong \\
\hline & & $\begin{array}{l}\text { Equal profits } \\
\text { in all sectors }\end{array}$ & $\begin{array}{c}\text { Profits only } \\
\text { in selected } \\
\text { industries }\end{array}$ & & & \\
\hline (1) & Share of capital and profits & 48.4 & 48.4 & 25.6 & 29.7 & 37.6 \\
\hline (2) & Growth in share of capital and profits & -0.1 & -0.1 & -0.3 & -0.9 & 0.8 \\
\hline (3) & Estimated "true" capital cost share & 34.0 & 31.5 & 32.8 & 27.1 & 34.6 \\
\hline (4) & Growth in "true" capital cost share & 0.4 & 0.8 & 0.2 & -0.1 & 0.6 \\
\hline (5) & Estimated "true" capital revenue share & 26.5 & 23.7 & 36.3 & 26.1 & 33.0 \\
\hline (6) & Growth in "true" capital revenue share & 0.7 & 1.3 & 0.4 & 0.3 & 0.5 \\
\hline (7) & Estimated Profit Share & 21.9 & 24.7 & -10.6 & 3.6 & 4.5 \\
\hline (8) & Growth in Profit Share & -1.0 & -1.4 & -2.1 & -9.2 & 3.1 \\
\hline
\end{tabular}

Notes: Line 1 shows the capital shares used by Young $(1995,1998)$ and also by Hsieh $(2002)$. Line 3 is calculated as a weighted average of Sarel's (1997) capital share estimates, with the weights determined by the industry-share of GDP (1-digit SIC from the CEIC database). Line 7, the estimated profit share of revenues, is calculated as $\left(1-s_{L}-\alpha\right) /(1-\alpha)$, where $\alpha$ is the capital share of cost shown in line 3. (In line 8, since Taiwan's profit rate was negative and becoming more negative, we report the average change in the profit rate divided by the absolute value of the mean profit rate.) Finally, the capital share in revenues (line 5) is equal to Young's capital share (line 1) minus the estimated profit share (line 7). Numbers may not add up due to rounding. 
Table 3: Benchmark Calibration Results and Robustness Checks (Except where indicated, all entries are percent per year)

\begin{tabular}{|c|c|c|c|c|c|}
\hline & Benchmark & With ROE & $\begin{array}{c}\text { (Favored Capital)/ } \\
\text { (Unfavored Capital) } \\
=4\end{array}$ & $\begin{array}{l}\text { Capital's share of costs } \\
\text { increased by } 0.09\end{array}$ & $\begin{array}{c}\text { labor's share of } \\
\text { revenue increased by } \\
0.08\end{array}$ \\
\hline Technology Growth & (1) & (2) & (3) & (4) & $(5)$ \\
\hline Unfavored Sector & 1.5 & 1.4 & 1.5 & 1.3 & 1.4 \\
\hline Favored Sector & -1.3 & -1.3 & -0.9 & -1.1 & -0.6 \\
\hline Aggregate Economy & -0.2 & -0.2 & 0.1 & -0.1 & 0.2 \\
\hline
\end{tabular}

Notes: Benchmark calculated using methodology described in Section 4. Aggregate technology calculated from sectoral technologies as $\widehat{a}=\omega_{U} \widehat{a}_{U}+\omega_{F} \widehat{a}_{F}$. Column (2) includes Hsieh's ROE-based measurement of the cost of capital in the average used to generate $\widehat{r}_{U}$. Column (3) increases the ratio of favored to unfavored capital from 2.1 to 4. Column (4) halves the aggregate profit share by arbitrarily increasing the capital share of costs (taken from international data) by 9 percentage points in every 1-digit sector. Column (5) halves the aggregate profit share by arbitrarily increasing the labor share of revenue estimate used in both the primal and dual by 8 percentage points. Numbers may not add up due to rounding. 
Table 4: Decomposing the Sources of Difference in Primal and Dual Estimates (Except where indicated, all entries are percent per year)

\begin{tabular}{|c|c|c|c|c|c|}
\hline & & Singapore & Taiwan & Korea & Hong Kong \\
\hline $\begin{array}{l}\text { (1a) } \\
\text { (1b) }\end{array}$ & $\begin{array}{l}\text { Real Wage Growth } \\
\text { Young (implied) } \\
\text { Hsieh }\end{array}$ & $\begin{array}{l}1.8 \\
3.1\end{array}$ & $\begin{array}{l}4.0 \\
5.4\end{array}$ & $\begin{array}{l}4.2 \\
4.4\end{array}$ & $\begin{array}{l}3.6 \\
4.1\end{array}$ \\
\hline $\begin{array}{l}(2 a) \\
(2 b)\end{array}$ & $\begin{array}{l}\text { Real Capital Payment Growth } \\
\text { Young (implied) } \\
\text { Hsieh }\end{array}$ & $\begin{array}{c}-3.0 \\
0.4\end{array}$ & $\begin{array}{l}-3.4 \\
-1.1\end{array}$ & $\begin{array}{l}-4.3 \\
-4.1\end{array}$ & $\begin{array}{c}0.1 \\
-0.6\end{array}$ \\
\hline (3) & Labor's Share (sample average) & 51.6 & 74.4 & 70.3 & 62.4 \\
\hline $\begin{array}{l}\text { (4a) } \\
(4 b)\end{array}$ & $\begin{array}{l}\text { Technology Growth } \\
\text { Primal Estimate } \\
\text { Dual Estimate }\end{array}$ & $\begin{array}{c}-0.5 \\
1.8\end{array}$ & $\begin{array}{l}2.1 \\
3.7\end{array}$ & $\begin{array}{l}1.7 \\
1.9\end{array}$ & $\begin{array}{l}2.3 \\
2.3\end{array}$ \\
\hline (5) & Labor's Contribution to TFP Gap & 0.7 & 1.0 & 0.1 & 0.3 \\
\hline (6) & Capital's Contribution to TFP Gap & 1.6 & 0.6 & 0.1 & -0.3 \\
\hline (7) & Difference (Dual - Primal) & 2.3 & 1.6 & 0.1 & 0.0 \\
\hline
\end{tabular}

Notes: Sample periods are adjusted to match Hsieh (2002). Lines (1b) and (2b) are the averages across the different measures reported by Hsieh (for which sample periods occasionally differ slightly). For Singapore, Young's primal data are taken from updated figures in Young (1998), other data are derived from Young (1995, Tables V, VII, and IX). Young's tables include data by subperiod for $\widehat{y}, \widehat{l}, \widehat{k}, s_{L}$ and $s_{K}$; we derive (implicit) growth in real factor prices from $\widehat{w}=\widehat{s}_{L}+\widehat{y}-\widehat{l}$ and $\widehat{r}=\widehat{s}_{k}+\widehat{y}-\widehat{k}$. We use a weighted average of growth rates over subperiods to adjust Young's numbers to cover the identical time period as each of Hsieh's measures (e.g., for a measurement of the 1973-1990 rate, we would take $7 / 17$ of the 1970-1980 rate and add it to 10/17 of the $1980-1990$ rate). The periods are all highly similar and approximately cover $1970-1990$. When original growth rate calculations are needed (i.e. growth of average labor share), the best approximation to end points are used (i.e. for 1975-1990 growth rates, the calculation might use the 10-year growth from the average during the 1970-1980 period to that during 1980-1990). For Taiwan, data exclude agriculture and include Young's adjustment of public sector output. Numbers may not add up due to rounding. 
Table 5: Contributions to the Difference in Primal and Dual Estimates for Singapore (Except where indicated, all entries are percent per year)

\begin{tabular}{|c|c|c|c|}
\hline (1) & Dual user cost & 0.4 & \\
\hline (2) & + Observable tax-correction term & & -0.9 \\
\hline (3) & $\begin{array}{l}\text { + Reallocation towards favored (low } \\
\text { user cost) sector }\end{array}$ & & -0.5 \\
\hline (4) & + Profits relative to capital & & -1.4 \\
\hline (5) & $\begin{array}{l}\text { + Residual (additional heterogeneity or } \\
\text { measurement error) }\end{array}$ & & -0.6 \\
\hline (6) & Primal (implied) payments to capital & -3.0 & \\
\hline
\end{tabular}

Notes: Using the calculations in Tables 2 and 3, plus the disaggregation of the capital-payments contribution to the dual-primal gap in equation (13), and finally taking into account the gap attributable to the tax correction, we calculate lines 1 through 4 above. Numbers may not add up because of rounding. 
Table 6: Contribution of Corporate Taxes to the User Cost

\begin{tabular}{ccccc}
\hline & Singapore & Taiwan & Korea & Hong Kong \\
\hline & $(1)$ & $(2)$ & $(3)$ & $(4)$ \\
\hline $\begin{array}{c}\text { Observable Tax } \\
\text { Correction Term }\end{array}$ & -0.9 & -0.6 & -0.3 & 0.0 \\
$\begin{array}{c}\text { Tax Contribution to } \\
\text { Difference (Dual - } \\
\text { Primal) }\end{array}$ & 0.4 & 0.2 & 0.1 & 0.0 \\
\hline
\end{tabular}

Notes: The top line shows the estimated growth rate in the aggregate tax adjustment. The second line shows the contribution to the dual-primal gap. 


\section{Figures}

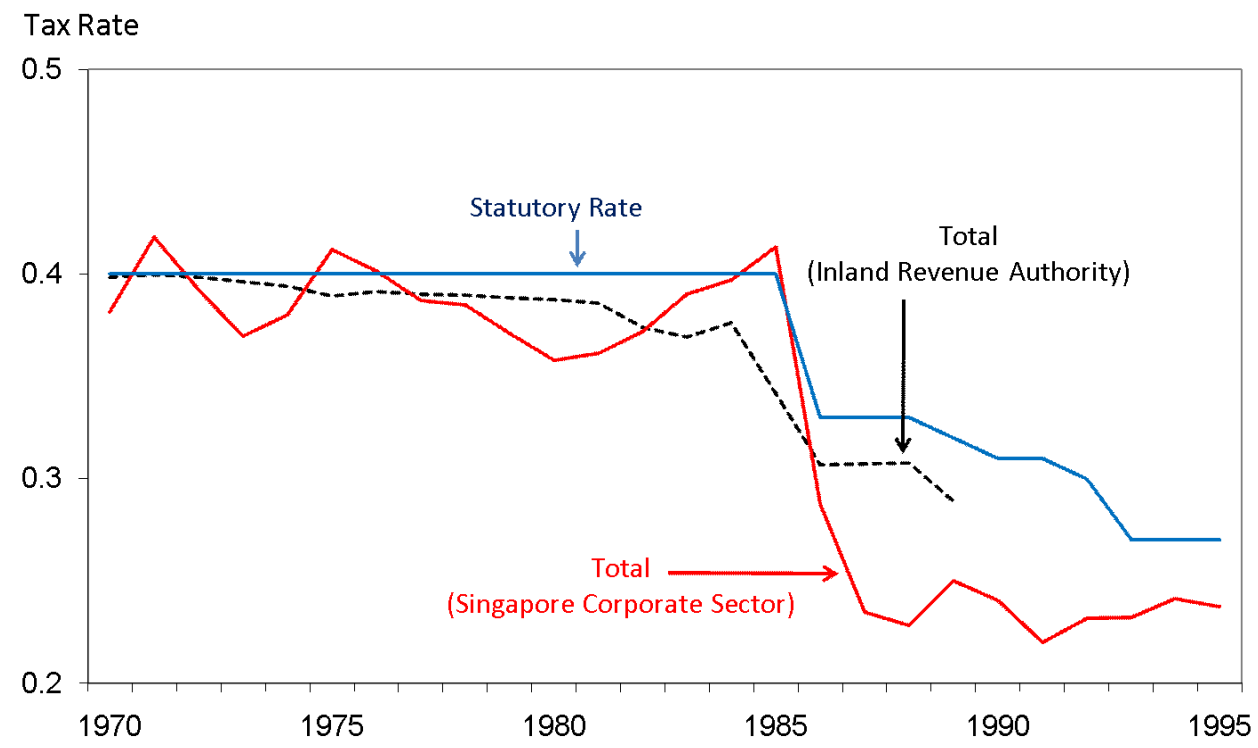

Figure 1A: Statutory Tax Rate and Average Rates Paid

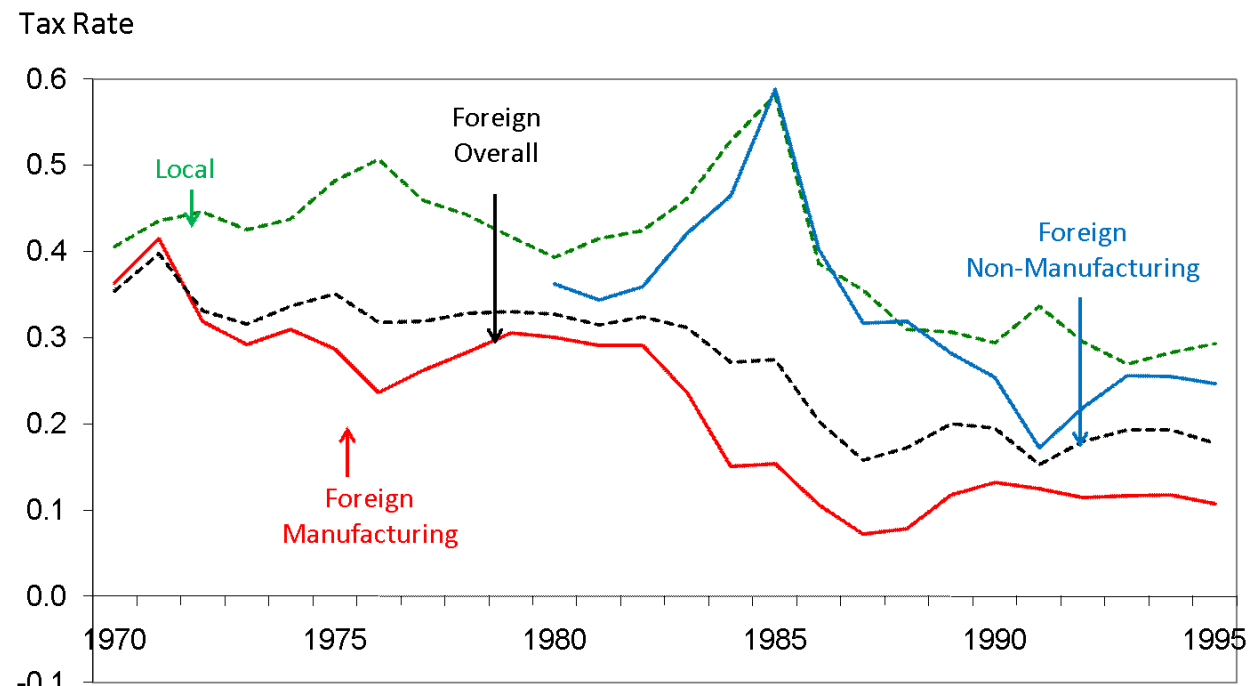

Figure 1B: Average Rates Paid for Different Firms

Notes: Sources are Inland Revenue Authority (various years) and Department of Statistics, Singapore (1992b, 1995, and 2006). See Appendix B for more information on data sources, including foreign manufacturing rate. 


\section{Appendix A: Aggregation, TFP, and Technology}

This appendix derives the relationships in section 2 on sectoral and aggregate TFP and technology in a two-sector economy. ${ }^{37}$

We begin by discussing the Divisia index for aggregate output: $\widehat{y} \equiv \omega_{F} \widehat{y}_{F}+\omega_{U} \widehat{y}_{U}$, where the nominal output share of sector $i$ is $\omega_{i} \equiv P_{i} Y_{i} /\left(P_{F} Y_{F}+P_{U} Y_{U}\right) \equiv P_{i} Y_{i} / P Y$. With this definition, a change in sectoral output translates into a change in aggregate output by an amount that depends on relative prices. To see this, suppose that, say, favored output rises. The change in the level of aggregate output is $d Y=Y \widehat{y}=\left(P_{F} / P\right) d Y_{F}$. Since purchasers' marginal rates of substitution depend on relative prices, the Divisia aggregate is thus a very natural measure of output in most models. ${ }^{38}$

Using the Divisia index, we can now write aggregate TFP growth as:

$$
\begin{aligned}
\widehat{y}-s_{L} \widehat{l}-\left(1-s_{L}\right) \widehat{k} & =\sum_{i=F, U} \omega_{i}\left(\widehat{a}_{i}+\alpha_{i} \widehat{k}_{i}+\left(1-\alpha_{i}\right) \widehat{l}_{i}\right)-s_{L} \widehat{l}-\left(1-s_{L}\right) \widehat{k} \\
& =\widehat{a}+\left(\sum_{i=F, U} \omega_{i} \alpha_{i} \widehat{k}_{i}-\left(1-s_{L}\right) \widehat{k}\right)+\left(\sum_{i=F, U} \omega_{i}\left(1-\alpha_{i}\right) \widehat{l}_{i}-s_{L} \widehat{l}\right) .
\end{aligned}
$$

The last term in parentheses is a weighted average of the contribution of labor to output in the two sectors, minus aggregate labor growth multiplied by labor's aggregate share. Aggregate labor growth, in turn, is $\hat{l}=\sum_{j=F, U}\left(L_{j} /\left(L_{F}+L_{U}\right) \hat{l}_{j}\right.$ We can write that last term out and rearrange as:

$$
\sum_{i=F, U} \omega_{i}\left(1-\alpha_{i}\right) \widehat{l}_{i}-s_{L} \widehat{l}=\sum_{i=F, U} \frac{W L_{i}}{P Y}\left(\frac{P_{i} Y_{i}}{R_{i} K_{i}+W L_{i}}-1\right) \widehat{l}_{i}
$$

The term on the right-hand-size of (A2) corresponding to $i=U$ is zero because, with no pure profits in the unfavored sector, $P_{U} Y_{U}=R_{U} K_{U}+w L_{U}$. For the $i=F$ term, note that $P_{F} Y_{F} /\left(R_{F} K_{F}+w L_{F}\right)=$ $1+\Pi_{F} /\left(R_{F} K_{F}+w L_{F}\right)$, so the overall expression simplifies considerably:

$$
\sum_{i=F, U} \omega_{i}\left(1-\alpha_{i}\right) \widehat{l}_{i}-s_{L} \widehat{l}=\left(1-\alpha_{F}\right) s_{\Pi} \widehat{l}_{F}
$$

Note that we have used the assumption that all profits are in the favored sector, so $\Pi=\Pi_{F}$. In essence, the only reason the aggregate estimate $s_{L} \widehat{l}$ differs from the share-weighted output contribution of the individual sectors is because of profits, which occur only in the favored sector.

Now consider the first, capital-growth-related, term in parenthesis in the second line of equation (A1). Noting that $1-s_{L}=s_{K}+s_{\Pi}$ and $R=\sum\left(K_{i} / K\right) R_{i}$ (which implies $R_{i}-R=$

\footnotetext{
${ }^{37}$ Basu and Fernald $(2001,2002)$ provide related derivations and discussion.

${ }^{38}$ In discrete time, the Tornquist approximation to the Divisia index is fairly natural, where growth rates are measured as log-changes, and shares are measured as the average in periods $t-1$ and $t$. Many statistical agencies use chain-aggregated output, which is also a discrete-time analogue of the Divisia index.
} 
$\left(K_{-i} / K\right)\left(R_{i}-R_{-i}\right)$ for $\left.i=F, U\right)$, we can express this term as:

$$
\begin{aligned}
\sum_{i=F, U} \omega_{i} \alpha_{i} \widehat{k}_{i}-\left(1-s_{L}\right) \widehat{k} & =\sum_{i=F, U}\left(\frac{R_{i} K_{i}}{P Y}\right)\left(\frac{P_{i} Y_{i}}{R_{i} K_{i}+W L_{i}}-\frac{R}{R_{i}}\right) \widehat{k}_{i}-s_{\Pi} \widehat{k} \\
& =\left(\frac{\Pi_{F}}{P Y}\right)\left(\frac{R_{F} K_{F}}{R_{F} K_{F}+W L_{F}}\right) \widehat{k}_{F}+\sum_{i=F, U}\left(\frac{K_{i}\left(R_{i}-R\right)}{P Y}\right) \widehat{k}_{i}-s_{\Pi} \widehat{k} \\
& =\left(\frac{\Pi_{F}}{P Y}\right)\left(\frac{R_{F} K_{F}}{R_{F} K_{F}+W L_{F}}\right) \widehat{k}_{F}+\sum_{i=F, U} \frac{K_{i} K_{-i}}{P Y} \frac{\left(R_{i}-R_{-i}\right)}{K} \widehat{k}_{i}-s_{\Pi} \widehat{k} \\
& =s_{\Pi}\left(\alpha_{F} \widehat{k}_{F}-\widehat{k}\right)+\frac{K_{F} K_{U}}{K P Y}\left(R_{F}-R_{U}\right)\left(\widehat{k}_{F}-\widehat{k}_{U}\right) .
\end{aligned}
$$

Combining (A1), (A3), and (A4), we have equation (7) in section 3.3: TFP $=\widehat{a}+s_{\Pi}\left(\widehat{x}_{F}-\widehat{k}\right)+\Sigma_{K}$. Thus, revenue-share-weighted TFP growth differs from technology growth because of two termsone which reflects profits and one which reflects reallocations of capital across uses.

The profits term, $s_{\Pi}\left(\widehat{x}_{F}-\widehat{k}\right)$, looks unusual, since it is the difference between favored input growth and aggregate capital growth. But it reflects the net effect of two ways in which profits coming from markups affect aggregate TFP growth. First, with markups, a factor's output elasticity in the favored sector exceeds its share in revenue (see, e.g., equation (1)); hence, we do not fully account for the productive contribution of favored inputs; the undermeasurement is $s_{\Pi} \widehat{x}_{F}$. Second, standard TFP subtracts off $\left(s_{K}+s_{\Pi}\right) \widehat{k}$, and the $s_{\Pi} \widehat{k}$ portion does not represent payments that correspond to capital's productive contribution to output.

The capital reallocation term reflects the fact that, for any given markups, the equilibrium marginal product is higher if the user cost is higher. Hence, if we shift capital from sectors with low user costs to sectors with high user costs, productivity rises.

Using a cost-share-weighted aggregate residual would change the form of these terms, but would not eliminate them. Let $\omega_{i}^{C} \equiv$ Cost $_{i} /$ Cost $=\left(R_{i} K_{i}+W L_{i}\right) /(R K+W L)$ be the share of sector $i$ in cost. Note that $\alpha=\omega_{F}^{C} \alpha_{F}+\omega_{U}^{C} \alpha_{U}$ and $1-\alpha=\omega_{F}^{C}\left(1-\alpha_{F}\right)+\omega_{U}^{C}\left(1-\alpha_{U}\right)$. It is straightforward to show that cost-share-weighted aggregate inputs equals cost-share-weighted sectoral inputs, plus a capital reallocation term:

$$
(1-\alpha) \widehat{l}+\alpha \widehat{k}=\omega_{F}^{C} \widehat{x}_{F}+\omega_{U}^{C} \widehat{x}_{U}-\left(1-s_{\Pi}\right)^{-1} \Sigma_{K}
$$

The capital reallocation term is a scaled-up version of the reallocation term from the standard residual; the scaling factor $\left(1-s_{\Pi}\right)^{-1}=P Y /$ Cost reflects that cost-weighted inputs use cost rather than revenue as their base. But aggregate output (appropriately) is measured using relative prices, not relative costs. Noting that $\omega_{U}^{C}=1-\omega_{F}^{C}$ and $\omega_{U}=1-\omega_{F}$, it follows that:

$$
\begin{aligned}
\widehat{y}-(1-\alpha) \widehat{l}-\alpha \widehat{k} & =\omega_{F} \widehat{y}_{F}+\omega_{U} \widehat{y}_{U}-\omega_{F}^{C} \widehat{x}_{F}-\omega_{U}^{C} \widehat{x}_{U}+\left(1-s_{\Pi}\right)^{-1} \Sigma_{K} \\
& =\widehat{a}+\left(\omega_{F}-\omega_{F}^{C}\right)\left(\widehat{x}_{F}-\widehat{x}_{U}\right)+\left(1-s_{\Pi}\right)^{-1} \Sigma_{K}
\end{aligned}
$$

The first reallocation term, $\left(\omega_{F}-\omega_{F}^{C}\right)\left(\widehat{x}_{F}-\widehat{x}_{U}\right)$ represents a shift among sectors where the profit rate differs, since profits drive a wedge between shares in revenue and shares in cost. In the special case where only the favored sector earns profits, this wedge $\left(\omega_{F}-\omega_{F}^{C}\right)=s_{\Pi} \omega_{U}^{C}=s_{\Pi} \omega_{U} /\left(1-s_{\Pi}\right)$. Intuitively, profits create a wedge between the revenue and cost shares; but if the unfavored sector is small (as measured by $\omega_{U}^{C}$ ), then the favored sector is already most of revenue and cost — so the 
wedge between $\omega_{F}$ and $\omega_{F}^{C}$ has to be small.

This profits reallocation term is positive (pushing up the cost-based residual relative to technology) if inputs are reallocated toward the favored sector. Economically, this reflects that output is measured using relative market prices, not relative costs of production. With differential profit rates, relative prices need not equal relative costs of production (i.e. the marginal rate of substitution is not equal to the marginal rate of transformation). Output is (quite appropriately) aggregated using prices, which are equated to marginal rates of substitution, not using marginal rates of transformation.

Both the capital and profits reallocation term reflects reallocations of resources among uses where the social values (measured by prices) of marginal products are different.

\section{Appendix B: Data Sources and Discussion}

This appendix corroborates key measures that we use from previous authors and the national accounts, and details our construction of additional data series.

\section{Confirming Singapore's Labor Share}

To verify the labor share figures used by Young (1994) and Hsieh (2002), we used the GDP by income components data from Singapore Statistics. These data were produced for the first time in the late 1990s, so they were not available when Young did his work; they are available only back to 1980. We want factor shares in output measured in prices received by producers, i.e., at so-called "basic prices." This is a concept intermediate between GDP at factor cost and GDP at market prices, in that it includes those business taxes that correspond to the use of a factors of production, such as property taxes, license fees, motor vehicle registration fees, and so forth; it also includes capital subsidies (which are a form of capital income). Singapore Statistics produces data on gross value added at basic prices as part of their GDP-by-industry data. Labor income in the GDP-by-income-components data include wages and salaries (whether in cash or in kind) as well as pension contributions. ${ }^{39}$

From 1980 to 1990, labor's share of income averaged 45 percent. This share incorporates all forms of employee compensation, including employers' contributions to the Central Provident Fund and private pension/insurance funds. It does not include unallocated proprietors' income from selfemployment, which averaged 8 percent of income over this period. Any reasonable allocation of this unallocated proprietors' income (such as $2 / 3$ to labor and $1 / 3$ to capital) would imply that labor's share was about $1 / 2$. Labor's share is often low in developing countries because self-employment income (e.g., from farming) is not allocated to labor. Gollin (2002) reports that after correctly allocating proprietors' income (i.e. self-employment income), labor shares are almost always in the range of 0.65 to 0.8 . In Singapore, the magnitude of unallocated proprietors' income is too small to explain the low labor share. The GDP-by-income-component data do suggest that labor's share might have edged up modestly over time, even as Singapore's industry structure was shifting towards capital-intensive sectors.

To measure factor shares, Young's figures use the input-output tables, which properly incorporate all capital-related taxes in capital income (i.e., they correspond to gross value added at basic

\footnotetext{
39 "Compensation of Employees (Employees' Remuneration): Payments of wages and salaries, pensions and allowances by resident producers to their employees. Such payments may be in cash or in kind. Contributions to pension funds (both paid or imputed), as well as various welfare schemes, eg, social security, family allowance, casualty insurance, life assurance are included as part of compensation of employees." ( http://www.singstat.gov.sg/statsres/glossary/economy.html, downloaded April 8, 2008.)
} 
prices). In 1990, the input-output tables have a labor share of 44 percent. (Close to the 45 percent share in the more recently produced GDP-by-income-components data, which incorporate more recent revisions including minor methodological changes.) Young then imputes wages for proprietors and unpaid family workers using micro data. Gollin cites Young (1995) as exemplifying the "best approach" to estimating factor shares (Gollin, p. 467). Despite differences in data sources, his figures are fairly consistent with the income-components data.

A few studies have proposed replacing Singapore's actual labor share of $1 / 2$ with a more "normal" labor share of 2/3. (For example, IMF, 2004) One justification, as in Sarel (1997), is that such shares might better measure true shares in cost. In our two-sector model, however, it is not appropriate to simply use aggregate cost shares - one needs to estimate technology change from the bottom up. (See Appendix A.)

In our view, one needs to understand why labor's share is so low: One cannot arbitrarily adjust it because it is out of line with other economies. In any case, adjusting capital's share down doesn't reconcile Young with Hsieh. Young's figures still imply that capital returns fell at nearly 3 percent per year, whereas Hsieh's suggest that the user cost was about constant.

\section{National Accounts Investment, Capital, and Industry Output}

GDP by expenditure data for Singapore were downloaded from Singapore Statistics, via CEIC Asia. (CEIC is a private data distributor.) These data include detailed investment data, which we used to construct aggregate capital stocks. In particular, gross fixed capital formation data by sector (public and private) and by type of capital (residential buildings, nonresidential buildings, other construction and works, transport equipment, and machinery and equipment) from 1960 to 2005 were downloaded from CEIC Asia Database on March 17, 2006. Real investment is measured in $\mathrm{S} \$ 2000$ prices.

These investment data were used to construct perpetual inventory measures of each type of capital stock. Depreciation rates follow Hsieh: Residential $=0.013$, nonresidential buildings $=$ 0.029 , other construction $=0.021$, transport $=0.182$, and machinery and equipment $=0.138$. Initial 1960 values of each type of capital stock were estimated by using the steady-state assumption that $K_{i .1960}=I_{i, 1960} /\left(g_{i}+\delta_{i}\right) ; g_{i}$ was approximated by the average rate of investment growth from 1960 to 1965 . The average depreciation rate in the economy, weighted by nominal values of capital, was 6.7 percent.

Capital input aggregates are measured as share-weighted growth rates (i.e., as Tornquist indices). The weights are estimated user costs of each type of capital, measured as a constant real interest rate equal to 0.05 plus the depreciation rate, multiplied by the nominal value of each type of capital. Growth in this weighted capital input measure is not very sensitive to the assumed real interest rate.

One-digit GDP-by-industry data for the NIEs are also from CEIC and were downloaded in February 1999. For Hong Kong, CEIC (and, as of this writing, the current national accounts) only contains industry data from 1980-1990, so we used industry data for 1970-79 from United Nations $(1979,1984)$. (For 1980, shares lined up very closely from the two sources.) For Singapore, we also downloaded updated data on February 2, 2006. The updated data include owner-occupied dwellings as a separate industry; rental housing, however, remains a part of the much broader "finance, insurance, and real estate." GDP by income component were purchased from Singapore Statistics (http://shop.asiaone.com/stores/singstat/gdi.html) on February 1, 2006. For comparisons with the United States, Dale Jorgenson's industry dataset for the United States was downloaded from http://post.economics.harvard.edu/faculty/ jorgenson/data/35klem.html (October 2002). When necessary, data are aggregated using Tornquist indices. 


\section{TFP Estimates}

Dual data calculations are from Hsieh (2002). ${ }^{40}$ Primal estimates are from Young $(1995,1998)$. To corroborate the figures reported by Young, we purchased the Singapore Statistics series on multifactor productivity (obtained via email February 23, 2006). The Singapore Statistics figures are available from 1973 on; the major conceptual difference from Young is that they do not adjust labor or capital for quality or composition. Average unadjusted TFP growth was only 0.7 percent per year from 1973-90 - indeed, TFP growth was negative from 1973-1985. These figures are very close to Young's unadjusted TFP growth from 1970-90. Young's input-composition adjustment removes about 1.2 percent per year from his unadjusted figures. We also estimated capital services (adjusted for composition) directly using national accounts data, as discussed above. These figures are also close to Young's figures on capital growth, and on growth in the capital-output ratio.

\section{Surpluses of Statutory Boards}

Current surpluses of seven major statutory boards are from the Economic Survey of Singapore (various issues). The seven are the Housing and Development Board (HDB), Jurong Town Corp (JTC), Public Utilities Board (PUB), Port of Singapore Authority (PSA), Telecommunications Authority of Singapore (Telecoms), Urban Redevelopment Authority (URA), and Sentosa Development Corp (SDC). Singapore Statistics confirmed in personal correspondence on March 20, 2006 that current surpluses of SBs that produce market output are included in corporate gross operating surplus.

\section{Government Loans and Bank Loans by Industry}

Information on Singapore's direct government loans were from the annual publication of Singapore's Treasury, "Financial Statements." (Singapore Treasury (various years). "Financial Statements." Government Printing Office, Singapore.) This publication included a list of loans made to particular borrowers. For example, for 1974, when Hsieh reports market interest rates that average 10 percent, the government made (among many others) a 5.5 percent loan to Jurong Shipbuilders, a 5.75 percent loan to Sentosa Development Corporation, and a 6.5 percent loan to Singapore Airlines. We tabulate these data from the annual publications and calculate a weighted-average interest rate for each year. After 1979, however, the Financial Statements cease to publish the interest-rate information on the loans, just the quantities.

Sources for bank loans by industry (showing that only 21 percent of loans to non-bank customers went to manufacturing, transport, and communications) are various issues of the Monetary Authority of Singapore Monthly Statistical Bulletin and Monthly Digest of Statistics. These sectors account for 40 percent of GDP, according to the national accounts' GDP by industry data discussed earlier. Inflows of foreign direct investment are from International Financial Statistics.

\section{Pre-Tax Income and Taxation by Industry in Singapore}

Provisions for taxes by local-controlled and foreign-controlled firms as well as by sector are from Department of Statistics, Singapore (1992b, 1995, 2006). These rely on corporate financial reports, and also report net income by sector as well as selected balance sheet information.

Hsieh (2002) used assessed corporate taxes from various annual reports of the Inland Revenue Authority (we thank him for making his data available). These report assessed taxes (which sometimes differ from taxes paid (see Asher, 1989). The Inland Revenue and corporate-sector data track reasonably well, but note that we do not expect them to track perfectly. For example, total

\footnotetext{
${ }^{40}$ Downloaded on June 13, 2003 from http://www.wws.princeton.edu/chsieh.
} 
corporate-reported net earnings include firms that make losses, and hence owe no tax; this raises the average rate paid, especially in recessions. In contrast, the Inland Revenue measure of assessed income is for firms owing tax, not for all firms, so it excludes this source of volatility. In addition, corporate net income uses accounting measures of depreciation whereas assessed income uses tax depreciation.

For U.S. multinationals, we thank Ariel Burstein for providing cross-country average-tax-rate data in summary form. For additional data on U.S. MNC operations in Singapore, we used the Bureau of Economic Analysis (BEA) annual survey of U.S. direct investment abroad. Files from 1983 onward were downloaded in March 2006 from http://www.bea.gov/bea/ai/iidguide.htm\#link12b. Earlier data were obtained from the BEA in hardcopy. Desai, Foley, and Hines (2002) have an extensive discussion of these data. We also used these data to calculate labor's share of value added for U.S. multinationals, where value added is given by compensation plus net income plus depreciation plus taxes other than on income and payroll (e.g., motor vehicle fees).

\section{Return on Equity and Net Fixed Assets}

Asset data taken from the Department of Statistics, Singapore (1992a). This is the report cited by Hsieh as the source of ROE data; but ROA data (not ROE data) are found in the report. Numbers consistent with Hsieh's ROE calculations are found in Department of Statistics, Singapore (1995). Department of Statistics, Singapore (1992b, 1995, 2006) also includes book-value estimates of net fixed assets (NFA) in the corporate sector.

\section{Present Value of Depreciation Allowances}

To calculate the present value of depreciation allowances in Singapore, we consider the four major types of non-residential capital identified in the national accounts: Machinery, transport equipment, industrial buildings, and other construction. (We exclude residences, even for private investment, on the grounds that a large share of it is owner-occupied rather than business-owned.) Commerce Clearing House (various years) and Inland Revenue Authority (various years) provide detailed information on the nuances of the tax code. These sources identify the initial and annual allowances, as well as the type of accounting required - declining balance or straight-line; they identify industries and activities that qualify for accelerated depreciation; and identify selected other incentives. The major changes over the 1970-90 period are (i) in 1978, initial and annual allowances for industrial buildings become much more generous; (ii) in 1980, allowances for transport and machinery become more generous because of the move from declining-balance to straight-line depreciation; and, (iii) some manufacturing firms were able to take advantage of considerably accelerated depreciation starting in 1980.

We assume that other construction received the same treatment as industrial buildings. In terms of (iii), we assume that most "favored" firms did not take advantage of this accelerated depreciation for equipment, since a majority of manufacturing firms (many of whom were foreign) already had pioneer status. A firm with pioneer status (and thus a low or even zero tax rate) would generally prefer to preserve some of the depreciation for the post-pioneer period, when income became taxable. However, we allow non-pioneer manufacturing firms (producing about 40 percent of manufacturing value added) to receive this accelerated depreciation beginning in 1980. In the late 1980s, accelerated depreciation for equipment became available to all firms, which would accentuate the rise in the present value of depreciation allowances relative to our conservative calculation, and hence would accentuate the decline in the tax-adjusted user cost of capital.

We use a constant nominal interest rate of 8 percent to calculate the present value of allowances 
$D_{i}$ for each type of capital. We confirmed that results are not sensitive to using other rates (e.g., 6 percent or 10 percent), or to using the actual time series on interest rates used by Hsieh (2002).

We do not, in general, need an overall weighted average $D$. Instead, we use these depreciationallowance estimates to calculate a separate tax adjustment $T_{i, j}$ for each type of capital $i$, differentiated by owner, $j$ : foreign manufacturing (where tax rates were lower; we also split this group into estimated pioneer and non-pioneer status to determine whether they benefited from accelerated depreciation) and non-foreign-manufacturing (where observed tax rates were higher, whether favored or unfavored). Where necessary, we weight these tax adjustments by estimated shares of capital income. Results are not particularly sensitive to the specific weights, since allowances for all types of capital became more generous.

\section{Estimating the Tax Rate for Foreign Manufacturing}

Department of Statistics, Singapore (1992b) provides summary profit/loss statements for Singapore's corporate sector beginning in 1980. These data have net income before tax (or profit/loss) as well as provisions for income tax, from corporate financial statements. These data are available for the entire corporate sector, as well by major industry, and for local-controlled versus foreigncontrolled firms within these industries. Hence, beginning in 1980 we can estimate the average tax rate by industry and owner. As noted in the text, these data indicate that the biggest divergence in average tax rates is for foreign manufacturing firms versus everyone else.

Prior to 1980, only selected data are available, but we can estimate the corresponding rate for foreign manufacturing firms. In particular, for the 1970-1979 period, Singapore Statistics provided us with selected data-including tax and income data-differentiated by local- versus foreign-controlled firms (but not broken out by industry). Conceptually, the overall tax rate for foreign-controlled firms (which these data contain) is the share-weighted average of foreign manufacturing and foreign non-manufacturing. We (i) assume manufacturing's share of net profits are proportional to their share of net fixed assets-and industry balance sheets (though not income statements) are available from Department of Statistics sources for the 1970s. We also (ii) assume that non-manufacturing firms pay the same average rate as local firms. These two assumptions allow us to estimate the rate for foreign manufacturing. For the period from 1980 on, the estimated rate from this method is quite similar to the actual observed rate. We splice the estimated and actual data in 1980. Results in the text appear robust to reasonable alternative choices, such as using the statutory rate for non-manufacturing firms, or using the (observed) 1980 value of manufacturing's share of income within MNC income.

\section{Estimating Tax Wedges for Favored and Unfavored Firms}

Sources of tax-rate data and details of the tax code include Fordham (1992), Commerce Clearing House (various dates), Inland Revenue Authority (various years), and Low et al. (1993). ${ }^{41}$

Figure 1B in the text shows that foreign manufacturing firms, who were major recipients of "pioneer" status, paid lower rates, which fell from about 40 percent to under 10 percent by 1990. Rates for other firms' (whether local and foreign) fell only to about 30 percent. To estimate the tax wedge for unfavored firms $T_{U}$, we use the statutory rate and the depreciation allowances discussed above. To estimate the wedge $T_{F}$, we assume that foreign manufacturing received preferential tax treatment, but other favored firms did not (those firms presumably received benefits in other forms, such as barriers to entry or unobserved capital subsidies $\kappa$ (land access, favorable loans, and the like) that we cannot account for in our calculations).

\footnotetext{
${ }^{41}$ We also downloaded data on May 17, 2006 from http://www.iras.gov.sg/ESVPortal/ct/ct_b.2.2_what+are+the+tax+rates.asp
} 
Foreign manufacturing accounted for about $1 / 3$ of total corporate profits and $2 / 3$ of foreign profits in the 1980s. We use the average tax rate for foreign manufacturing but assume that other firms (favored or unfavored) paid the statutory tax rate; we then use the capital-and-owner-specific present values of depreciation rates to calculate the tax wedges $T_{i, j}$ for each type of capital $i$ and by owner. Following Hsieh (2002), we fit a time trend to each estimate and divide by the mean. (One reason Hsieh uses this approach is that he can apply this procedure to data that might occasionally take on negative values - such as ex post rates of return - where one cannot use logs. But taking log-changes of the tax term gives similar results.) We then obtain a weighted growth in the tax wedge $\widehat{t}_{U}$ by weighting by estimated shares in capital payments. This wedge declined 0.7 percent per year for firms paying the statutory rate $\left(\widehat{t}_{U}=-0.7\right)$.

Foreign manufacturing firms faced a lower tax rate that fell more quickly. In addition, as noted in the earlier discussion of the depreciation allowances, one significant difference for favored firms was a 50 percent investment allowance introduced in 1980 for non-pioneer-manufacturing, which was in addition to other, regular allowances. We assume that 40 percent of foreign manufacturing firms received the investment allowance, based on the roughly 60 percent share of manufacturing production accounted for by pioneer firms. Overall, for foreign manufacturing, the tax wedge declined 1.3 percent per year.

To construct a weighted $\widehat{t}_{F}$, we weight $\widehat{t}_{F o r M F}$ and $\widehat{t}_{U}$ (the observable term for favored firms outside foreign manufacturing) by estimated payments to capital of foreign manufacturing in favored sectors versus other sectors. We use net fixed asset data (from corporate balance sheet information in Department of Statistics, 1992b and 2006) to get a ballpark estimate of $q K_{\text {For } M F} / q K_{\text {Favored }}=$ 0.39 , and multiply by our estimated ratio of $T_{\text {ForMF }} / T_{\text {Favored }}=0.95$ to construct the weights $T_{\text {ForMF }} q K_{\text {For MF }} / T_{\text {Favored }} q K_{\text {Favored }}=0.39$ We then estimate $\widehat{t}_{F}=0.39(-1.3)+(1-0.39)(-0.7)=$ -0.9 percent per year ${ }^{42}$

For section 5, we construct tax as a share-weighted average of $\widehat{t}_{U}$ and $\widehat{t}_{F}$. The calibration in Section 4 indicates that $R_{F} K_{F} / R K=\eta \beta /(1+\eta \beta)=0.60$, implying that that $\operatorname{tax}=-0.9$.

Although the decline in statutory rates was smaller than the decline in foreign manufacturing rates, the decline in $T_{i}$ was still large for firms outside the foreign manufacturing sector because of the increase in $D$. The calculations are fairly robust to alternative paths for the capital weight. We also confirmed that qualitative results were robust to a wide range of assumptions about depreciation allowances. Note that the declining tax wedge is consistent with a rising corporate tax-to-GDP ratio because corporate profits as a share of GDP were rising.

\section{Tax Parameters for Hong Kong, Korea, and Taiwan}

The main source of depreciation allowances and investment tax credits is various issues of Price Waterhouse's, "Corporate taxes, a worldwide summary." For Taiwan, other sources included Price Waterhouse, "Doing Business in Taiwan," 1989, 1991 and 1996, and Deloitte, Haskings, \& Sells "Taxation in Taiwan, ROC (Republic of China)" (1982). Tax rates were obtained by email from Taiwan's Ministry of Finance (April 2006) and from Chou and Wu (1994). For Korea, corporate tax rates are from Hyun et al (2000). Other sources were Price Waterhouse's "Doing Business in Korea" (1992). For Hong Kong, our sources were Ho (1979) and Ho and Chau (1988). We confirmed the depreciation schedules with Hong Kong's Inland Revenue Department. Further details on our

\footnotetext{
${ }^{42}$ In principal, there is also a reallocation term if capital is growing at a different rate in foreign manufactuing versus overall favored sectors. We expect that capital was growing quickly in all favored industries, and the nominal fixed-asset data do not suggest any large differences. Thus, the reallocation term is likely to be small.

Of course, between the favored and unfavored sectors, the differences in capital growth rates and levels of effective user costs appear much larger. This is why we define a term tax as the weighted-average component of the overall $\widehat{t}$.
} 
calculations are available from the authors.

\section{Calibrating Favored and Unfavored User Costs in Singapore}

We calculate the average level of the unfavored user cost (as a percentage of $q$, the price of capital) as $(\rho+\delta-\widehat{q}) T_{U}$. Earlier in this appendix, we estimated (see section on national accounts data) that $\delta=6.7$ percent. Hsieh's estimates of the real rate $\rho-\widehat{q}$ averages 4.4 percent (lending rate) or 5 percent (earnings-price ratio). We use 4.4 percent. Our calculation of $T_{U}$ averaged 1.17, yielding an average $R_{U} / q=13$ percent. For favored firms, we now need to take a stand on unobserved subsidies $\kappa$, which we did not do in our earlier estimate of $T_{F}$. We adjust $\kappa$ to correspond to an interest-rate subsidy of about 2 percentage points, which yields $T_{F}$ averaging about 0.83 and implies $R_{F} / q=9.24$ percent. (Note that we calibrate the unobserved subsidy level only to calibrate $K_{F} / K$ and $\widehat{k}_{F}$. As discussed in the text, choosing a smaller subsidy level (thereby raising $R_{F} / R_{U}$ ) would raise the estimated $\widehat{k}_{F}$ and further reduce favored technology.)

\section{Appendix C: Systematic National Accounting Errors?}

This appendix discusses the hypothesis, plausible in principle, that systematic errors in the national accounts could reconcile the primal and the dual. In particular, Hsieh (2002) suggests that the national accounts overstate growth in the capital-output ratio by about 3 percentage points per year. Hsieh's example of national accounting errors concerns output rather than investment: Singapore uses a low, subsidized rental rate to measure the service flow from owner-occupied housing. ${ }^{43}$ This suggests that the accounts might understate nominal housing, though not necessarily its real service flow, which rose 11 percent per year from 1970-1990. Nevertheless, suppose mismeasured housing services caused us to understate true output growth by 3 percent per year from the mid-1960s to 1990. Then by 1990, true output would have been more than twice its measured level (i.e., 3 percent compounded for 25 years) - making Singapore by far the richest country in the world, with owner-occupied housing accounting for over half of GDP. Singapore was quite wealthy by 1990, but these counterfactuals seem implausible. ${ }^{44}$

Could Singapore instead have overstated capital growth by 3 percentage points per year? Suppose there were growing errors in real investment from the mid-1960s on. Like most countries, Singapore measures expenditure from ongoing surveys of its components. Large errors in the investment surveys would not be offset by large errors in the consumption surveys. Hence, both output and the GDP deflator would also be mismeasured (and incorrect when used for the dual). But Singapore uses different surveys to measure GDP from the expenditure, output, and income sides. If expenditure-based nominal GDP were mismeasured, then there would counterfactually be a large and growing statistical discrepancy.

Might the investment deflator grow too slowly? After adjusting the machinery and equipment deflator for exchange-rate changes, the growth in Singapore's deflator rises about 2 percentage points per year faster than the U.S. deflator from 1970-1990 - consistent with Singapore not incor-

\footnotetext{
${ }^{43}$ If marginal rates of substitution reflect the subsidized rate then Singapore's treatment is appropriate. But if subsidized housing is quantity-rationed, then this rate is not the right shadow value.

${ }^{44}$ Non-housing TFP growth is virtually identical to overall TFP growth. Non-housing output rises 0.1 pp per year more slowly from 1970-1990 than overall output; non-housing capital grows 0.1 pp per year faster. In addition, labor's share of income increases by 0.02 (since housing services are part of capital income), so on balance, share weighted inputs rise about $0.1 \mathrm{pp}$ per year more slowly.
} 
porating hedonic adjustments into their deflators. ${ }^{45}$ Hence, Singapore plausibly understates rather than overstates real investment growth. ${ }^{46}$

A more plausible way to reduce capital growth is to raise the initial level of investment. In the 1960s, gross fixed capital formation averaged 18 percent of GDP; this share rose to 36 percent in the 1970s and to 40 percent in the 1980s. Suppose we raised the share of investment in GDP to 36 percent for each year from 1960-1969 and then reestimate capital growth. From 1970-90, this alternative capital series grows 3.2 percent per year less than what the national accounts suggest. (The 1960 level of capital is benchmarked as $I_{60} /(g+\delta)$, where $g$ is the average growth from 1960 to 1965; this alternative path raises the estimated initial capital level about nine-fold.)

Nevertheless, such an increase in initial investment and capital seems unlikely. First, it implies, counterfactually, a statistical discrepancy averaging 18 percent of GDP in the 1960s; the actual discrepancy was fairly small (see Young, 1998). Second, the 1960s were a time of political upheaval and civil unrest, so the investment climate was not particularly favorable relative to the '70s and '80s. Third, Young (1995) uses data on residential construction and retained imports of cement to extend structures investment back to 1947; those figures do not suggest widespread errors in the initial capital or investment values in the 1960s. Finally, Hsieh provides no evidence of major underestimates of initial investment and capital.

In sum, Hsieh has identified an interesting puzzle. But before relying on the unsupported hypothesis of large scale national accounting errors, one needs to assess other probable explanations.

\footnotetext{
${ }^{45}$ In personal correspondence (March 23, 2006), Singapore Statistics confirmed that they have not implemented any hedonic adjustments to their investment deflators.

${ }^{46}$ Such an adjustment would increase real capital growth and, hence, reduce primal TFP growth. It also would reduce the growth in the user cost and, hence, in the dual, since the user cost depends on the price of capital, $q$. But it would not affect the gap between the primal and the dual.
} 